\title{
Securitization and Moral Hazard: Evidence from Credit Score Cutoff Rules
}

\author{
Ryan Bubb and Alex Kaufman
}

\begin{abstract}
:
Mortgage originators use credit score cutoff rules to determine how carefully to screen loan applicants. Recent research has hypothesized that these cutoff rules result from a securitization rule of thumb. Under this theory, an observed jump in defaults at the cutoff would imply that securitization led to lax screening. We argue instead that originators adopted credit score cutoff rules in response to underwriting guidelines from Fannie Mae and Freddie Mac and offer a simple model that rationalizes such an origination rule of thumb. Under this alternative theory, jumps in default are not evidence that securitization caused lax screening. We examine loan-level data and find that the evidence is inconsistent with the securitization rule-of-thumb theory but consistent with the origination rule-of-thumb theory. There are jumps in the number of loans and in their default rate at credit score cutoffs in the absence of corresponding jumps in the securitization rate. We conclude that credit score cutoff rules provide evidence that large securitizers were to some extent able to regulate originators' screening behavior.
\end{abstract}

JEL Classifications: D82, G01, G18, G21, G24, G28.

Keywords: financial crisis, moral hazard, mortgages, securitization, credit scores

Ryan Bubb is an assistant professor of law at the New York University School of Law. His email address is ryan.bubb@nyu.edu. Alex Kaufman is an economist at the Board of Governors of the Federal Reserve System. His email address is alex.kaufman@frb.gov.

This paper presents preliminary analysis and results intended to stimulate discussion and critical comment. The views expressed herein are those of the authors and do not indicate concurrence by other members of the research staff or principals of the Board of Governors, the Federal Reserve Bank of Boston, or the Federal Reserve System.

This paper presents preliminary analysis and results intended to stimulate discussion and critical comment. The views expressed herein are those of the authors and do not indicate concurrence by other members of the research staff or principals of the Board of Governors, the Federal Reserve Bank of Boston, or the Federal Reserve System.

Financial support for this research was provided by the John M. Olin Center for Law, Economics, and Business at Harvard Law School. We thank Viral Acharya, Jennifer Arlen, Ken Ayotte, Michal Barzuza, Effi Benmelech, Stephen Choi, Andrew Eggers, Chris Foote, Josh Gallin, Ed Glaeser, Claudia Goldin, Robin Greenwood, Andrew Haughwout, Marcel Kahan, Larry Katz, Benjamin Keys, David Laibson, Doug McManus, Justin McCrary, David Scharfstein, Josh Schwartzstein, Amit Seru, Andrei Shleifer, Holger Spamann, Jeremy Stein, Joseph Tracy, James Vickery, Vikrant Vig, Glen Weyl, Larry White, Paul Willen, Heidi Williams, Noam Yuchtman, and numerous seminar participants for valuable comments and discussions. We thank Larry Cordell, Vidya Shenoy, and Mark Watson for their patient help with the LPS dataset. We are grateful to the research departments at the Federal Reserve Bank of Boston and the Federal Reserve Bank of New York for supporting this research. We thank Xiaoqi Zhu for outstanding research assistance. Much of the work of this paper was done while Bubb was supported as a Terence M. Considine Fellow in Law and Economics at Harvard Law School.

This version: August 30, 2011; first version: September 23, 2009 


\section{INTRODUCTION}

It has now become conventional wisdom that securitization contributed to the sharp rise in mortgage defaults that precipitated the recent financial crisis. The logic of the moral hazard problem posed by securitization is straightforward: lenders that sell loans they originate to dispersed investors may bear less of the cost when loans default, and hence they may have less incentive to screen borrowers. The belief that this moral hazard problem played an important role in the financial crisis has influenced regulatory reform, with the 2010 Dodd-Frank Act adopting a requirement that securitizers and/or originators retain a 5 percent interest in mortgages they securitize to better align their incentives. ${ }^{1}$

However, there are reasons to think that securitization may not have had a large moral hazard effect on lender screening. Mortgage securitization was developed over decades, and as early as 1993 the overall securitization rate was nearly as high as in the period leading up to the financial crisis. ${ }^{2}$ Lenders and securitizers both had strong incentives to devise ways to avoid the moral hazard problem posed by securitization, and a range of practices were indeed developed to mitigate it (Gorton, 2009). These include contractual provisions such as representations and warranties by lenders and clauses that require lenders to buy back loans that default soon after sale, monitoring strategies like the extensive underwriting guidelines and audits used by some large loan purchasers, and software systems that automate parts of the mortgage underwriting process. Hence, the extent to which securitization actually reduced lenders' screening is an empirical question.

One promising strategy for answering this question is to use variation in the behavior of lenders at credit score cutoffs. Credit scores are used by lenders as a summary measure of default risk, with higher credit scores indicating lower default risk. Despite the smoothness of the distribution of credit scores in the overall population, histograms of mortgage borrower credit scores, such as Figure 1, are step-wise functions with a series of discontinuities. It appears that borrowers with scores just above certain thresholds are treated differently than borrowers just below, even though potential borrowers on either side of the threshold are very similar. These histograms suggest using a regression discontinuity design to learn about the effects of the change in behavior of market participants at these thresholds.

\footnotetext{
${ }^{1}$ Section 941 of the Dodd-Frank Wall Street Reform and Consumer Protection Act, codified at 15 U.S.C. $§ 780-11$.

${ }^{2}$ For instance, 67.6 percent of new mortgage origination volume was securitized in 2006 compared with 65.3 percent in 1993 according to the 2010 Mortgage Market Statistical Annual, published by Inside Mortgage Finance.
} 
In this paper we distinguish between two explanations for credit score cutoff rules, each with opposing implications for what these cutoff rules tell us about the relationship between securitization and lender screening. We refer to the explanation currently most accepted in the literature as the securitization rule-of-thumb theory. First offered by Keys, Mukherjee, Seru, and Vig (2010b) (hereafter, KMSV), it posits that secondary-market mortgage purchasers employ a rule of thumb whereby they are exogenously more willing to purchase loans made to borrowers with $\mathrm{FICO}^{3}$ scores just above 620 than to borrowers with scores just below 620. KMSV exploits this rule of thumb in a regression discontinuity design to investigate the effect of securitization on lenders' incentives to screen. Examining a dataset of only securitized loans, the authors interpret discontinuities in loan performance at 620 as estimates of the causal effect of securitization on lender screening.

However, two assumptions are crucial to the validity of this research design. First, there must be a discontinuous increase in the probability of securitization at 620. In the terminology of instrumental variables (IV), we must have a valid first stage - the instrument (the 620 cutoff) must have an effect on the treatment of interest (the probability of securitization). KMSV's primary dataset, from LoanPerformance, contains only securitized loans, and KMSV does not show whether the fraction of loans securitized jumps at $620 .{ }^{4}$

Second, lenders' discontinuous change in screening at 620 must be entirely driven by the change in probability of securitization at 620. If lenders' behavior changes discontinuously for other reasons, then we cannot attribute the jump in defaults at 620 to securitization. In IV terms, this would be a violation of the exclusion restriction-the cutoff is affecting the outcome through a channel other than ease of securitization.

We consider an alternative theory for the origin of credit score cutoff rules, which we refer to as the origination rule-of-thumb theory, that implies a violation of this exclusion restriction. In particular, we argue that lenders adopted credit score cutoff rules directly in response to underwriting guidelines from Fannie Mae and Freddie Mac (the government sponsored enterprises, or GSEs).

\footnotetext{
${ }^{3}$ The credit scoring model developed by Fair Isaac and Company (FICO) is the industry standard.

${ }^{4}$ KMSV (pp. 345-347) does use the Lender Processing Services dataset that we use-which contains both securitized and portfolio loans - to examine whether there is a discontinuity in GSE loans at 620, but does not use it to report any first stage showing whether the fraction of securitized loans jumps at 620. KMSV does report that the number of securitized loans in its sample jumps at 620, but without knowing how large the corresponding jump in the number of non-securitized loans is, this is uninformative about the probability of securitization.
} 
This theory is based on institutional evidence that shows that in the 1990s, with the goal of improving underwriting, the GSEs required originators to adopt credit score cutoff rules to determine how carefully to screen mortgage borrowers. Moreover, these credit score cutoff rules spread widely through originators' use of underwriting software that incorporates the cutoffs. We offer a simple model based on discreteness in the cost of information collection for why the GSEs directed originators to adopt such credit score cutoff rules. Furthermore, the discontinuity in lender screening at the credit score cutoffs creates discontinuities in the amount of private information originators have about loans. Information asymmetry can inhibit trade, and hence origination rules of thumb can result in discontinuities in the securitization rate.

Importantly, the origination rule-of-thumb theory and the institutional evidence on which it is based imply a violation of the exclusion restriction of KMSV's research design. The independent change in lender screening intensity at the cutoffs confounds the effect of any change in ease of securitization, invalidating a regression discontinuity design based on these cutoffs. The jumps in default at credit score thresholds thus do not provide evidence that securitization led to lax screening.

Furthermore, using loan-level data we find large jumps in the number and default rate of loans at credit score cutoffs in the absence of corresponding first-stage discontinuities in the securitization rate. In IV terms, the first stage shows that the instrument has no effect on the treatment. Despite this, it has a large reduced-form effect on the outcome, confirming the exclusion restriction violation implied by the institutional evidence. We use data from Lender Processing Services that include both securitized and portfolio loans. Figure 8 presents our basic finding. Panels (a) and (b) reveal jumps in both the number of loans and the default rate at the FICO scores of 620 and 660, confirming the presence of lender screening cutoffs at those scores. However, panel (c) shows that there are no corresponding jumps in the securitization rate. These results are inconsistent with the securitization rule-of-thumb theory, but consistent with the origination rule-of-thumb theory.

Our findings provide evidence that securitizers were to some extent able to mitigate the incentive problems posed by securitization. When Fannie Mae and Freddie Mac, the two largest mortgage purchasers, determined that using credit score cutoff rules to determine how carefully to scrutinize loan applications could improve mortgage underwriting, they included credit score cutoff rules in their underwriting guidelines. The ubiquity of the 620 and 660 FICO credit score cutoff rules in the 
mortgage markets is a testament to the ability of Fannie and Freddie to enforce their underwriting guidelines through software, contractual provisions, and monitoring. Interpreted in light of our findings and analysis, the discontinuities in default at certain credit score thresholds do not provide evidence for the hypothesis that securitization led to lax screening. Rather, they provide evidence for the opposing hypothesis: large securitizers like Fannie and Freddie were to some extent able to regulate lenders' screening behavior.

KMSV investigated our thesis that credit score cutoff rules are used by lenders for reasons unrelated to the probability of securitization and attempted to test it based on evidence from the passage of anti-predatory lending laws in Georgia and New Jersey. KMSV's authors argue that these laws affected only the ease of securitization, and that the change in the discontinuity in default at 620 FICO when the laws were in effect shows that the cutoff rule in screening is due to a purchasing rule of thumb in the secondary market and is not used by lenders for other reasons.

However, there are three problems with this analysis. First, KMSV found no default rate discontinuity at 620 when the laws were not in effect (and securitization was unimpeded), and found a negative default discontinuity when the laws were in effect. These are not the results predicted by their securitization rule-of-thumb theory, as the 620 cutoff continued to operate during a time when, according to KMSV, securitization was inhibited. Second, contrary to KMSV's claim that the laws affected only ease of securitization, the laws' primary aim was to reduce default directly. Accordingly, the laws restricted a broad range of lending practices, such as loan "flipping" and negative amortization loans, and for certain types of loans required that lenders reasonably believe that borrowers would be able to make their payments. Therefore, the laws can be expected to have an effect on the default discontinuity at 620 under both cutoff rule theories and do not provide a test of the origination rule-of-thumb theory. Third, KMSV used a dataset containing only securitized loans and did not test whether the laws in fact had an effect on the securitization rate. Using a differences-in-differences approach we find that the laws had no effect on the securitization rate.

In response to an earlier version of this paper, the authors of KMSV wrote a response paper (Keys, Mukherjee, Seru, and Vig (2010a), hereafter KMSV2). ${ }^{5}$ We respond in detail to the issues raised in KMSV2 in a companion paper, Bubb and Kaufman (2011), which we summarize in section 6 of this paper. KMSV2's principal claim is that our finding of discontinuities in the default

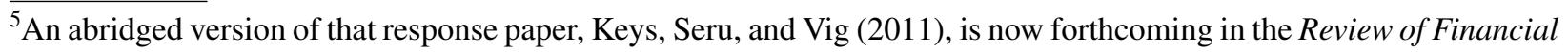
Studies. 
rate at credit score thresholds without corresponding discontinuities in the securitization rate is an artifact of pooling loans sold to private-label securitizers with loans sold to the GSEs. The authors of KMSV2 argue that there are two separate markets: (1) the "non-agency market" of loans only at risk of being purchased by private-label securitizers; and (2) the "agency market" of loans only at risk of being purchased by the GSEs. They assume that loans are either in one market or the other and that no loan is simultaneously at risk of being bought by private-label securitizers and by the GSEs. Moreover, they argue that the 620 FICO rule of thumb was used only by private-label securitizers and not by the GSEs, and that by pooling together loans in these two markets, we have attenuated the discontinuity in securitization (KMSV2, p. 14).

However, the evidence is inconsistent with KMSV2's separate markets assumption. We look to the data and find that 18 percent of loans in our 2003-2007 conforming sample were at one point owned by the GSEs and at another point owned by private-label securitizers-a lower bound on the proportion that were simultaneously at risk of being sold to both types. Moreover, institutional evidence shows that the GSEs and private-label securitizers actively competed over subprime loans in the secondary market during this period. The fact that many loans were simultaneously at risk of being sold to the GSEs and to private-label securitizers implies that GSE loans and privatelabel securitized loans, as well as portfolio loans, must be pooled together in order to correctly estimate the probability of securitization at any given FICO score, as we do in our analysis of the conforming sample.

We furthermore show that discontinuities in the lending rate and default rate exist for loans other than private-label securitized loans. We show that these discontinuities exist for loans that were owned by the GSEs and that the lender cutoff rules in screening persist in 2008-2009, after the private-label market had shut down. Moreover, we find a discontinuity in default in the absence of a discontinuity in the probability of securitization in our jumbo sample, which is an exclusively non-agency market.

Finally, KMSV's selection of only low-documentation loans results in posttreatment selection bias. The level of documentation required by lenders for a loan is a measure of the outcome of interest, lender screening. Selecting on the outcome variable causes KMSV's regression discontinuity estimates of the change in lender screening at 620 FICO to be biased. Valid causal inference requires that any subgroups be defined by plausibly predetermined, exogenous variables 
only. Hence we subgroup only by loan size, origination year, and FHA / VA status, and offer a breakdown by documentation status only for comparability with KMSV's estimates.

Our paper contributes to a burgeoning literature analyzing the causes of the subprime mortgage crisis. A growing number of papers rely on the securitization rule-of-thumb theory to interpret the cutoff rule evidence, including Keys, Mukherjee, Seru, and Vig (2009), Krainer and Laderman (2009), Keys, Mukherjee, Seru, and Vig (2010b), Jiang, Nelson, and Vytlacil (2010), Rajan, Seru, and Vig (2010), and Keys, Seru, and Vig (2011). Mayer, Pence, and Sherlund (2009) documents many of the basic facts of the subprime crisis and concludes that a combination of a decline in underwriting standards and a fall in house prices led to the sharp increase in defaults from 2005 to 2008. Further evidence on the central role of the fall in housing prices in the mortgage crisis is provided by Gerardi, Shapiro, and Willen (2007). Demyanyk and Van Hemert (2009) provides evidence that the increased future default rates of high LTV loans were to some extent priced into the mortgage rate well before the onset of the crisis, suggesting that securitizers who influence those rates were aware of the coming increase in defaults. The connection between securitization and the increase in defaults is investigated by Jiang, Nelson, and Vytlacil (2009), Elul (2009), Mian and Sufi (2009), and Demiroglu and James (2011). Downing, Jaffee, and Wallace (2009) explores whether the market for mortgage backed securities is a lemons market. Adelino, Gerardi, and Willen (2009) and Piskorski, Seru, and Vig (2008) investigate whether securitization inhibited modifications of loans for distressed borrowers.

Our work also relates to the literature on loan sales more generally. Gorton and Pennacchi (1995), Pennacchi (1988), and Sufi (2007) consider institutional mechanisms to mitigate the moral hazard problem in screening and monitoring posed by loan sales, including the use of portfolio loans as an incentive instrument. Drucker and Puri (2008) documents the use of loan covenants to address agency problems in loan sales.

The paper proceeds as follows. Section 2 describes the securitization rule-of-thumb theory and its implications for using credit score cutoffs to learn about the effect of securitization on screening. Section 3 presents the competing origination rule-of-thumb theory and the institutional evidence on which it is based. Section 4 tests predictions of the competing theories with evidence from a loan-level dataset. Section 5 presents analysis of the Georgia and New Jersey law changes. Section 6 summarizes KMSV2 and our response, Bubb and Kaufman (2011). Section 7 concludes. 


\section{SECURITIZATION RULE-OF-THUMB THEORY}

Why might lenders adopt credit score cutoff rules? The theory currently most accepted in the literature, first offered in KMSV, is that lenders adopt credit score cutoff rules solely in response to a rule of thumb followed by securitizers in their purchasing decisions. This rule of thumb made securitizers more willing to buy mortgage loans made to borrowers with FICO scores of 620 or above than loans to those with scores of 619 or below. KMSV (pp. 318-319) argues that this rule of thumb originated from advice from the GSEs that FICO scores below 620 indicate much riskier borrowers. Importantly, the authors assume that lenders did not respond to this GSE guidance directly. Rather, they argue that only private-label securitizers and MBS investors followed this advice of the GSEs by adopting the purchasing rule of thumb. In later work, they also argue that the GSEs did not follow this rule of thumb in their own purchasing decisions (Keys, Mukherjee, Seru, and Vig, 2010a). We refer to this theory as the securitization rule-of-thumb theory.

KMSV argued that, if the securitization rule-of-thumb theory is true, one can use the variation in secondary market demand for loans to estimate the causal effect of securitization on lender screening. Figure 2 provides a graphical depiction of KMSV's research design based on the securitization rule-of-thumb theory. The pools of potential borrowers with FICO scores of 619 and 620 are very similar. But when originators consider applicants from each of these pools, the probability they can sell the loans made to the two pools is different because of the rule of thumb followed by purchasers in the secondary market. In particular, the probability they can sell a 620 loan is higher than the probability they can sell a 619 loan. Or equivalently, the probability that a 620 loan stays on the originator's books ("in portfolio") is lower than the probability that a 619 loan stays on the originator's books. This reduction in "skin in the game" for loans made to 620 borrowers results in more lax originator screening behavior for 620 applicants as compared to 619 applicants. The result is that more loans are made to 620 borrowers and that those loans default at a higher rate. Hence, KMSV ascribes the difference in probability of default between the 620 and 619 borrowers to the discontinuous change in the probability of securitization.

However, this research design is based on two identification assumptions. First, lenders must face a discontinuously greater probability of selling loans at 620 than at 619 . This is equivalent to the IV assumption that there be a valid first stage. The instrument $Z \in\{0,1\}$ is an indicator for whether a loan is made to a borrower with a FICO score greater than or equal to 620. For 
KMSV's research design to be valid, $Z$ must have an effect on (more precisely, a non-zero partial correlation with) the treatment of interest, the probability of securitization, when other covariates are controlled for. KMSV does not report a first stage showing that the probability of securitization changes discontinuously at 620. The primary dataset the authors use is composed entirely of securitized loans and hence is uninformative about the probability of securitization.

A second identifying assumption of this RD research design is that there is no reason for the default rate to discontinuously change at the 620 threshold other than in response to a change in ease of securitization. ${ }^{6}$ In standard RD designs, this assumption is formulated as a continuity assumption on the conditional expectation of the outcome variable. ${ }^{7}$ It can also be expressed in IV terms as an exclusion restriction. The reduced form effect of the 620 cutoff on default can be interpreted as the causal effect of the change in probability of securitization at the cutoff only if the 620 cutoff does not have an effect on defaults through any channel other than its effect on the probability of securitization (the exclusion restriction). If instead there is a reason for the default rate to discontinuously change at 620 even if the securitizers' behavior did not change at that cutoff, then one cannot estimate the causal effect of any change in probability of securitization at 620 by estimating the change in default rates at 620 .

Furthermore, even if these identification assumptions hold, this research design cannot distinguish a moral hazard effect of securitization on lender screening from the general effect of credit expansion on the identity of the marginal borrower. The purchasing rule of thumb in the secondary market posited by KMSV would shift outward the supply of credit for borrowers at 620, resulting in the marginal 620 borrower having a higher default risk than the marginal 619 borrower, even if the incentives of originators were perfectly aligned with the interests of securitizers and MBS investors (that is, in the absence of moral hazard). This credit supply effect would generate higher default rates at 620 than at 619 .

\footnotetext{
${ }^{6} \mathrm{KMSV}$ (p. 321) focuses on a necessary condition for this identifying assumption to hold, namely that there is not a discontinuous change in the credit quality of potential borrowers at 620 . However, this condition is not sufficient. It must also be the case that there is no reason for lenders' behavior to change discontinuously at 620 other than in response to a change in the probability of securitization.

${ }^{7}$ Imbens and Lemieux (2008) provide a general formulation of this identifying assumption in RD designs using a potential outcomes framework.
} 


\section{ORIGINATION RULE-OF-THUMB THEORY}

We elaborate an alternative theory for the origin of credit score cutoff rules. We argue based on institutional evidence that lenders responded directly to the underwriting guidelines of the GSEs, which required lenders to adopt credit score cutoff rules to determine how carefully to screen borrowers. Moreover, automated underwriting systems (AUSs) that incorporate cutoff scores led to widespread use of credit score cutoff rules. We refer to this theory as the origination rule-ofthumb theory. We begin by describing the institutional evidence that forms the basis for the theory and then offer a simple model that rationalizes the GSEs' guidance on credit score cutoff rules. Importantly, this theory and the institutional evidence on which it is based imply that the exclusion restriction for KMSV's research design is invalid, and therefore that credit score cutoff rules cannot be used to estimate the causal effect of securitization on lender screening.

3.1. The adoption of credit score cutoff rules by mortgage originators. Mortgage lenders began to incorporate FICO scores into their underwriting procedures in the mid-1990s (Straka, 2000). Lenders employed cutoff rules that required increased scrutiny of loan applicants below some threshold FICO score, and 620 quickly became a widely adopted threshold. Avery, Bostic, Calem, and Canner (1996, p. 628) describe the use of cutoff rules in mortgage lending thus:

To operate a scoring system for credit underwriting, a lender must select a cutoff score (such as 620) that can be used to distinguish acceptable from unacceptable risks. Regardless of the cutoff score selected, some customers with bad scores will be offered credit because of offsetting factors, and some customers with good scores will be denied credit, also because of offsetting factors.

Underwriting guidelines from the GSEs were an important catalyst of the mortgage industry's adoption of FICO scores. The GSEs had conducted research into the relationship between FICO scores and mortgage performance showing that "despite the fact that those borrowers who had FICO scores in the lower range (620 or less) represented only a very small percentage of the total universe, they (as a group) accounted for approximately 50 percent of the eventual defaults..." (Fannie Mae, 1995, p. 4).

In 1995 Freddie Mac sent a letter to originators establishing three tiers of credit scores in order to help originators "better assess and manage the quality of [their] loan originations, reduce servicing costs and sustain profitability" (Freddie Mac, 1995, p. 2). The FICO scores of 620 and 660 were key cutoffs. For borrowers with FICO scores above 660, lenders were to do a "basic" review 
to "underwrite the file as required to confirm the borrower's willingness to repay as agreed." For borrowers with FICO scores between 660 and 620, lenders were to perform a "comprehensive" review to "underwrite all aspects of the borrower's credit history to establish the borrower's willingness to repay as agreed." For borrowers with FICO scores below 620, lenders were warned to be "cautious" and to "perform a particularly detailed review of all aspects of the borrower's credit history to ensure that you have satisfactorily established the borrower's willingness to repay as agreed. Unless there are extenuating circumstances, a credit score in this range should viewed as a strong indication that the borrower does not show sufficient willingness to repay as agreed."

Fannie Mae (1997, pp. 8-9) established a similar set of credit score cutoffs, stating that applicants with FICO scores below 620 represent a "very high" risk of default, and "the underwriter must apply good judgment when he or she considers the unique circumstances of each application" and "if there are sufficient compensating factors or extenuating circumstances that offset the higher risk of default associated with credit scores in this range, the underwriter may approve the financing." In contrast, for borrowers with scores above 660, Fannie Mae required that the lender only verify that the credit history is complete.

Importantly, the GSEs did not establish 620 as a minimum threshold for loans to be eligible to be sold to the GSEs. Loans above and below 620 remained eligible for purchase by the GSEs. Fannie Mae (1997, p. 13) stated: "There are several compensating factors that are acceptable for offsetting a FICO Bureau Score below 620. We do not specify a minimum FICO Bureau Score that must be attained before an underwriter can consider approving an applicant for mortgage credit based on the existence of compensating factors." 8

Lenders who sell loans to Fannie Mae and Freddie Mac were contractually obligated to follow the GSEs' guidance letters establishing credit score cutoff rules for screening. ${ }^{9}$ In addition to a lawsuit for breach of contract, lenders who did not follow the GSEs' underwriting guidelines

\footnotetext{
${ }^{8}$ See also Cassidy and Englestad (1998): "Fannie Mae constantly and consistently communicates to our lenders that we will purchase mortgages with credit scores below 620 .... Freddie Mac has repeatedly advised lenders that a credit score of 620 should not be viewed as an absolute threshold."

${ }^{9}$ As Fannie Mae's April 1, 2009, Single Family Selling Guide (p. 11) states: "Lenders are bound by and must comply with the [Mortgage Selling and Servicing Contract], the Selling Guide and Servicing Guide (including any Announcements or Lender Letters), and any other applicable agreement(s) a lender has entered into with Fannie Mae, as they currently exist or as they may be revised. The lender's obligations under all of these agreements are referred to in this Guide in their entirety as the 'Lender Contract.' "
} 
were at risk of having their relationship with the GSEs terminated. ${ }^{10}$ Accordingly, lenders widely adopted the GSEs' rules on the use of FICO scores, including the use of the FICO score thresholds they recommended for gathering additional information about borrowers' creditworthiness.

3.2. Automated underwriting systems encode the credit score cutoff rules. Another way credit score cutoff rules spread was through their incorporation into automated underwriting systems (AUSs), which became widely adopted beginning in the mid-1990s (Hutto and Lederman, 2003). Most mortgage originators use either the Desktop Underwriter (DU) program, created by Fannie Mae, or the Loan Prospector (LP) program, created by Freddie Mac. These and other similar programs take as inputs information such as FICO score, loan-to-value ratio, and debt-to-income ratio, and quickly compute a recommendation.

When lenders get an "approve" or "accept" recommendation from their AUS, that is usually the end of the process and they approve the loan. When they receive a "refer" or "caution" recommendation, they may then begin the process of manual underwriting (Hutto and Lederman, 2003). ${ }^{11}$ Manual underwriting is similar to underwriting as it was done before the advent of AUSs. The lender collects additional information, such as information about non-standard sources of income, cash reserves, and the applicant's explanation of recent income or payment shocks. The lender may also conduct a face-to-face interview in order to gauge "character risk." The lender then makes a holistic judgment to determine whether to extend credit. Hutto and Lederman (2003, p. 201) write:

[W]ith the advent of the statistical systems used by AUSs, the "accept" and "approved" loans are now more science than art. However, those loans ranked "refer" or "caution" do still require the use of the underwriting art since the evaluation of compensating factors is involved... Automated underwriting has allowed underwriters to focus on those loans where mortgage bankers most need their special expertise - that is, in the refer/caution area where underwriting judgment is critical.

Because DU and LP are designed and distributed by the GSEs, which require lenders to use 620 and 660 as cutoffs, these cutoffs were coded directly into the AUS decision rules. ${ }^{12}$ Though AUSs calculate default risk using smooth functions of FICO score, they also employ a layer of

\footnotetext{
${ }^{10}$ Freddie Mac (2001), Chapter 5, "Disqualification or Suspension of a Seller/Servicer" details the process by which Freddie Mac can terminate its relationship with an originator.

${ }^{11}$ Notably, "reject" is not one of the recommendations given by AUSs. They merely "refer" the lender to a more thorough underwriting protocol (Fannie Mae, 2007).

${ }^{12}$ Personal communication with Freddie Mac executives, October 9th, 2009. Fannie Mae changed DU in 2000 to calculate its own risk rating based on the underlying credit report data (Quinn, 2000), but FICO scores are still required to evaluate loans in DU (Fannie Mae, 2007).
} 
"overwrites" which are triggered when borrowers fall into certain categories-for instance, borrowers with FICO scores below 620. The effect is that a loan to a borrower with a FICO of 620 is discontinuously more likely to receive an "approve" recommendation from the AUS than a similar borrower with a FICO of 619. As a result, lenders following AUS recommendations are discontinuously more likely to initiate manual underwriting for a borrower with 619 FICO than for a borrower with 620 FICO. Loans that are "referred" are still eligible for purchase by the GSEs (and private securitizers) so long as the lender judges them to be acceptable through its manual underwriting process. ${ }^{13}$ Securitizers commonly buy loans that are initially referred and later approved through the manual underwriting process.

DU and LP were quickly adopted as the industry standard and used not only for loans sold to the GSEs but also for portfolio loans and loans sold to private-label securitizers, including jumbo loans for amounts above the GSEs' conforming loan limits. When it created LP in 1995, Freddie Mac worked with Standard \& Poor's to validate LP for loans that did not meet Freddie Mac's eligibility requirements. Subprime and jumbo originators, such as IndyMac, adopted DU or LP to underwrite loans that were sold to private-label securitizers. ${ }^{14}$ And private-label securitizers often required originators to use DU or LP as their automated underwriting system. ${ }^{15}$ Competitors to DU and LP did emerge, such as Countrywide's CLUES software and GMAC-RFC's Assetwise software, many of which also rely on FICO scores (Poon, 2009).

\subsection{A rational model of credit score cutoff rules. Why did the management of the GSEs be-} lieve that using a credit score cutoff rule to determine how carefully to screen potential borrowers would help originators "better assess and manage the quality of [their] loan originations" (Freddie Mac, 1995, p. 2)? In general, lenders face nondivisible, discrete screening decisions: whether to manually underwrite a loan, whether to conduct a face-to-face interview, and so on. We posit that the discreteness of such decisions implies that the optimal lender screening strategy takes the form of a credit score cutoff rule or set of cutoff rules.

\footnotetext{
${ }^{13}$ In addition to the approve/refer recommendation, DU presents a separate eligible/ineligible output that tells the lender whether the loan violates one of Fannie Mae's eligibility guidelines, such as limits on loan size. Until 2008 there was no minimum FICO score that would make a loan ineligible, and since 2008 Fannie Mae still allows exceptions to the minimum credit score requirements for certain manually underwritten loans (Fannie Mae, 2011).

${ }^{14}$ Press Release, "Freddie Mac, Indy Mac, and Standard \& Poor's use technology to set industry standard for entire single-family mortgage market," (1996).

${ }^{15}$ For example, see Washington Mutual Home Loans (2006).
} 
This rationale for credit score cutoff rules can be formalized in a simple model. Suppose that there is a continuum of prospective borrowers of unit mass. Each borrower has a credit score $x$ that represents hard information about the likelihood that the borrower will default. To economize on notation, let $x \in[0,1]$ represent both the borrower's credit score and the fraction of borrowers with that credit score who would repay a mortgage. For simplicity, the remaining $1-x$ fraction of borrowers with that credit score would default without making any payments on the mortgage. $x$ is distributed according to the strictly positive, continuous probability density function $f(x)$. Borrowers would like to take out a mortgage for 1 unit of the numeraire good at time 0 to be repaid with interest at time 1 , but they have an outside option such that they will refuse a loan offer with a gross interest rate above $\bar{R}>1$. There is a single risk-neutral lender with discount factor normalized to 1 . At time 0 each borrower applies to the lender for a mortgage. The lender observes each applicant's $x$.

The lender then chooses whether to further investigate each borrower's creditworthiness. To do so, the lender must bear a fixed cost $c>0$ per applicant. The fixed cost arises from discreteness in the information production function available to the firm managers who set underwriting policy. For example, requiring loan officers to meet with loan applicants in person, or to perform manual underwriting in addition to the commonly used computer-aided automated underwriting process, entails a fixed cost per applicant. Moreover, it would be difficult for managers (or the GSEs) to specify continuous investigation intensities for continuous distributions of borrowers, given difficulty in monitoring their agents' screening behavior (Ellison and Holden, 2008). Consequently, firm managers face a discrete choice set of investigation intensities. ${ }^{16}$

If the lender investigates and the borrower is a defaulter, the lender learns this with probability $s \in(0,1)$, and otherwise the lender observes nothing. The lender's investigation thus reveals this "defaulter signal" about a borrower with credit score $x$ with probability $(1-x) s$. We assume that $c<\frac{(\bar{R}-1) s}{\bar{R}}$ so that investigation is cheap enough that it will pay for the lender to investigate some applicants. The lender then chooses whether to lend to each applicant and, if so, makes a take-itor-leave-it interest rate offer $R(x)$. Those offered loans then decide whether to accept the offer. In period 1, borrowers learn whether they are defaulters, and the nondefaulters pay the lender $R(x)$.

\footnotetext{
${ }^{16}$ Though for simplicity we model a binary investigation choice, the model could be extended to accommodate multiple levels of discrete investigation intensity, each with its own cost: $c_{1}<c_{2}<c_{3} \ldots$ and so on. Each discrete level of investigation would induce a separate threshold, a prediction consistent with the observation of multiple thresholds in the data (see Figure 1). However, a binary choice captures the essence of the theory.
} 
Obviously the lender never chooses to lend to applicants for which its investigation revealed the defaulter signal. Furthermore, because we have given the lender all of the bargaining power, it should be obvious that, if the lender lends, it is a dominant strategy to offer $\bar{R}$, and for all borrowers offered a loan to accept. ${ }^{17}$ Hence, the equilibria of the game are characterized by an investigation strategy (which borrower types the lender investigates) and a lending strategy (to which types the lender offers loans). We now have our main result:

Proposition 1. In the unique equilibrium, the lender uses cutoff rules based on a lending threshold $\underline{x}=\frac{1-s+c}{\bar{R}-s}$ and a screening threshold $\bar{x}=1-\frac{c}{s}>\underline{x}:$

(1) The lender rejects borrowers with $x<\underline{x}$

(2) The lender investigates borrowers with $\underline{x} \leq x<\bar{x}$ and offers loans to those for which its investigation does not reveal the defaulter signal.

(3) The lender offers loans to borrowers with $x \geq \bar{x}$ without investigation.

All proofs are in Appendix A.

This screening behavior by lenders results in a discontinuous jump in the density of loans at the $\bar{x}$ screening threshold, depicted in Figure 5, and a similar jump in the default rate of loans, depicted in Figure 6. The intuition for how these discrete costs result in discontinuities in default rates is straightforward: if lenders gave stricter scrutiny to loan applicants just above the $\bar{x}$ threshold it would reduce the default rate, but this reduction would not justify bearing the fixed cost $c$ per applicant to collect the information. In contrast, for loan applicants just below the $\bar{x}$ threshold the benefit of additional information outweighs the fixed cost.

Our simple model provides a rationale for the GSEs' expressed belief that requiring originators to follow a credit score cutoff rule would improve underwriting. As with the credit score $x$ in the model, there is a continuous, monotonic relationship between FICO score and default risk. Mapped into our model, a FICO score such as 620 corresponds to the screening threshold $\bar{x}$.

The GSEs were uniquely well suited to bring about the adoption of such a credit score cutoff rule. As guarantors for the vast majority of mortgages, they had much more data on mortgage

\footnotetext{
${ }^{17}$ It is possible to complicate the model by making $R$ a decreasing function of $x$, but it does not yield new insights. Under reasonable assumptions the single crossing property still holds and lenders still employ a cutoff rule.
} 
performance than any single lender (Poon, 2009). Moreover, they stood to gain from the industrywide improvement in underwriting that adoption of credit score cutoff rules by originators could bring about.

It is also not surprising that the GSEs created a single set of cutoffs that they required all originators to use. It would likely have been prohibitively costly for the GSEs to tailor the precise cutoffs that they required to the specific circumstances of each originator. Reliance on AUSs is another reason why, even though the fixed cost $c$ may theoretically vary among originators, originators coordinated on a few key FICO thresholds. ${ }^{18}$

It is unlikely that the credit score cutoff rules required by the GSEs were perfectly optimal. For example, if other information in the loan application is predictive of mortgage performance, the optimal credit score cutoff rule would vary from applicant to applicant, based on these other covariates. Optimal screening rules under such multidimensionality would result in a smoother marginal distribution of FICO scores than the distribution in Figure 1. Rather, we think of credit score cutoff rules as imperfect but useful rules of thumb in the spirit of Baumol and Quandt (1964).

3.4. Implications for securitization. Credit score cutoff rules can also result in discontinuities in the securitization rate at the credit score thresholds. Originators' greater investigation of applicants below the screening threshold results in originators' having greater private information about those loans than the loans above the cutoff. This increase in information asymmetry can inhibit trade in mortgages. If a loan purchaser, which we will refer to somewhat imprecisely as a securitizer, bargains with an originator over the purchase of loans, it will face an adverse selection problem. The lender would like to originate and sell to the securitizer loans that it knows are lower credit quality, keeping for itself the high credit quality loans. As in Akerlof (1970), asymmetry of information on borrower quality can inhibit trade. Because the amount of private information changes discontinuously at the screening threshold, this adverse selection problem can cause the volume of trade - that is, the securitization rate — to change discontinuously at the same threshold.

If instead the originator and securitizer can bargain over a loan purchase contract prior to the originator's making investigation and lending decisions, a moral hazard problem arises. If the

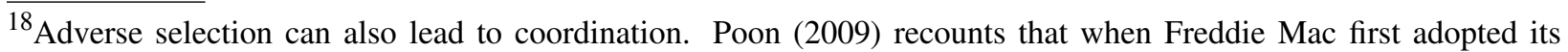
FICO score screening thresholds in 1995, Fannie Mae swiftly followed by adopting the same thresholds because "they suddenly found themselves besieged ... by loans that passed through their rule-based [non-FICO] guidelines but which were adversely selected because many had already been ... rejected by Freddie."
} 
contract specifies that a loan to a particular potential borrower will be sold, then the originator will have no incentive to investigate the borrower and make efficient lending decisions. One incentive instrument that the securitizer can use to mitigate this problem is portfolio loans. The contract can specify that only a fraction of loans (of some type) will be sold, with the particular loans chosen at random and the rest of the loans remaining on the books of the originator to maintain its incentives to screen. ${ }^{19}$ An originator cutoff rule in screening can result in a discontinuity in the securitization rate under this moral hazard setup. Because it is efficient to screen more below the screening threshold, the originator has to retain a larger fraction of loans under the screening threshold to maintain its incentives to screen. ${ }^{20}$

The origination rule-of-thumb theory thus predicts that, when information is asymmetric, credit score cutoff rules in screening may produce corresponding discontinuities in the securitization rate. More generally, there are many characteristics of loans that affect the likelihood that originators will sell the loan. The change in lender screening produces a different pool of loans on each side of the credit score cutoff, and these differences may result in different securitization rates. Crucially, any securitization rate discontinuities that result would be consequences, not causes, of the discontinuities in lender screening.

Of course, securitizers may use a range of incentive instruments other than portfolio loans to mitigate the problem of asymmetric information. Securitizers commonly audit loans to check whether underwriting conforms to the standards set out in their contract, and may sue or force the originator to buy back the loan if it does not. ${ }^{21}$ Even in the case that screening is not observable through audits, as long as underwriting quality can be inferred from default outcomes a large securitizer can use the threat of contract termination to discipline originators. ${ }^{22}$ If securitizers use such alternative incentive instruments, or if they ignore the change in lender screening intensity entirely,

\footnotetext{
${ }^{19}$ This is indeed a standard practice. See Comptroller of the Currency (1997, p. 14).

${ }^{20} \mathrm{We}$ analyzed the moral hazard case formally in an extension of our model in an earlier version of this paper, Bubb and Kaufman (2009).

${ }^{21}$ The recent $\$ 8.5$ billion settlement by Bank of America of litigation brought by MBS investors charging that Bank of America violated its representations and warranties with respect to mortgages that Countrywide, now a subsidiary of Bank of America, originated and sold to be securitized is a (belated) example of this.

${ }^{22}$ For example, Freddie Mac (2001), Chapter 5, "Disqualification or Suspension of a Seller/Servicer" details the process by which Freddie Mac can terminate its relationship with an originator. The GSEs do indeed terminate sellers who violate their underwriting guidelines. For example, New Century Financial Corp., a subprime lender, was terminated by Fannie Mae in March, 2007. See “New Century says cut off by Fannie Mae," Reuters, March 20, 2007.
} 
we may observe a securitization rate that is continuous through the cutoff under the origination rule-of-thumb theory.

3.5. Discussion. For the changes in default at these credit score thresholds to be interpreted as the causal effect of securitization on lender screening, an exclusion restriction must hold. This identification assumption is depicted in Figure 3. KMSV's RD research design requires that the GSEs' underwriting guidelines for originators affected the decisions of private-label securitizers, which they suppose adopted a purchasing rule of thumb in response to the guidelines. The exclusion restriction, represented by the crossed-out arrow from the GSEs to originators, requires that the GSEs' underwriting guidelines for originators had no direct effect on the decisions of originators.

The institutional evidence that forms the basis of the origination rule-of-thumb theory, on the other hand, is depicted in Figure 4. It shows that the GSEs' guidance on credit score cutoff rules was directed at originators. Moreover, these credit score cutoff rules were incorporated into the GSEs' contracts with originators and into underwriting software that was widely used in the industry, including for loans sold to private-label securitizers. Even if securitizers did follow purchasing rules of thumb at those same thresholds, any resulting incentive effect would be confounded by originators' independent use of cutoff rules in screening and by the effect of the discontinuous change in GSE guidance and AUS output at those same thresholds. Moreover, the origination ruleof-thumb theory implies that causality can run opposite to the direction supposed by the securitization rule-of-thumb theory. By introducing discontinuities in the amount of private information that originators have about loan applicants, the cutoff rule used by originators can potentially induce discontinuities in the securitization rate.

The institutional evidence thus makes the identifying assumptions underlying KMSV's RD research design implausible. The discontinuity in defaults at credit score thresholds should therefore not be taken as evidence that securitization caused lax lender screening. Instead they show that the two largest securitizers, Fannie Mae and Freddie Mac, were to some extent able to regulate lenders' screening behavior. 


\section{Quantitative Evidence}

We analyze loan-level data to further distinguish the origination rule-of-thumb theory from the securitization rule-of-thumb theory.

4.1. Data. Our data come from Lender Processing Services Applied Analytics, Inc. (LPS). These are loan-level data collected through the cooperation of mortgage servicers, including the 10 largest servicers in the United States. Originators commonly contract with outside servicers who manage the day-to-day collection of mortgage payments. ${ }^{23}$ All of the loans in LPS were either originated by one of the contributing servicers or had their servicing rights sold to one of these servicers. LPS contains privately securitized loans, GSE-purchased loans, and portfolio loans (loans for which the originator retains rights to the payment stream). ${ }^{24}$ The data cover over half of outstanding mortgages in the United States and contain more than 32 million active loans. Key variables in the dataset include borrower FICO scores, detailed loan terms, monthly securitization status, and monthly loan performance data.

We select from LPS first-lien, non-buydown, owner-occupied, single-family mortgage loans originated between January 2003 and June 2009. Borrowers must have FICO scores between 500 and 800 to be included in the sample. ${ }^{25}$ In order to avoid survivorship bias, we eliminate loans that do not appear in the dataset by their sixth month after origination, even if they appear later. ${ }^{26}$

4.2. Measuring probability of securitization. Before detailing our estimation framework, we first clarify the relevant measure of securitization. An unusual aspect of KMSV's implementation of their empirical strategy is that they use a regression discontinuity design, where probability of securitization is the "treatment," using a dataset with only securitized loans. Using this dataset KMSV cannot estimate a first stage to confirm that there is a discontinuity at 620 in the probability

\footnotetext{
${ }^{23}$ An originator's decision to sell servicing rights is distinct from its decision to sell rights to the stream of payments from the loan itself. Some originators are also servicers. Servicing divisions of originating banks operate fairly autonomously and can buy servicing rights to loans not originated by the parent bank.

${ }^{24}$ We cannot distinguish between loans that GSEs hold in their own portfolio and loans that the GSEs securitize. However, the distinction is irrelevant for our purposes. For simplicity we use the term "securitized" to refer to all loans purchased on the secondary-market.

${ }^{25} 14.8$ percent of loans from LPS that meet our other sample selection criteria have missing FICO scores and are dropped from our analysis sample.

${ }^{26}$ Loans that first enter the dataset significantly after they are originated (so-called "seasoned" loans) can potentially lead to biased estimates. Those loans least at risk of terminating early, either through repayment or foreclosure, are often not typical of the greater population of loans, and such loans will be over-represented in seasoned data. For this reason we consider only loans with seasoning of 6 months or fewer.
} 
that loans are securitized. Instead, KMSV show that the number of loans in their dataset of securitized loans jumps at 620. Because the FICO distribution of potential borrowers is continuous at 620 , they argue that this shows that the "unconditional probability" of securitization (that is, the probability that a potential borrower is given a loan which is later securitized, rather than either not being given a loan at all or being given a loan that is kept in portfolio) jumps at 620 .

However, the probability relevant for testing the hypothesis that securitization diluted the screening incentives of lenders is the probability that a loan is securitized, not the probability a potential borrower is given a securitized loan. If a lender has a very high probability of selling a loan, say to a naive securitizer, then the lender's incentives to screen borrowers might be attenuated. If instead there is a large chance that the lender will keep the loan, then the moral hazard problem is less severe. This probability a loan is kept is what is usually meant by "skin in the game."

The unconditional probability in which KMSV demonstrates a jump conflates two different probabilities: (1) the probability that potential borrowers are given a loan, which we will refer to as the lending rate; and (2) the probability that loans are securitized, which we call the securitization rate. More formally, let $L_{i} \in\{0,1\}$ denote whether potential borrower $i$ is given a loan and let $S_{i} \in\{0,1, \emptyset\}$ denote whether borrower $i$ 's loan is securitized (with $S_{i}=\emptyset$ if borrower $i$ is not given a loan). KMSV's unconditional probability is then:

$$
\operatorname{Pr}\left(S_{i}=1\right)=\operatorname{Pr}\left(L_{i}=1\right) * \operatorname{Pr}\left(S_{i}=1 \mid L_{i}=1\right)
$$

The first factor on the right-hand side of this equation is the lending rate; the second factor is the securitization rate. KMSV shows that this product, measured as the number of securitized loans, jumps at 620 , but does not show whether this is because the lending rate jumps or because the securitization rate jumps. Our dataset contains both securitized and portfolio loans, enabling us to decompose the jump in the unconditional probability into jumps in the lending rate and securitization rate.

4.3. Subgroups. We divide the sample into two origination date time periods: a pre-crisis period of January 2003-December 2007, and a post-crisis period of January 2008-June 2009. Studying the pre-crisis period is of obvious importance for understanding the causes of the financial crisis. 
During the post-crisis period, private-label mortgage securitization shut down. Studying the postcrisis period provides another way to investigate whether the credit score cutoff rules in screening were exclusively caused by a rule of thumb in the private-label secondary market.

Because of the large influence of the GSEs, we split the 2003-2007 sample into a "conforming" sample of loans for amounts below the conforming loan limits, ${ }^{27}$ which the GSEs are bound to observe, and a jumbo sample of loans that exceed these limits. ${ }^{28}$ The GSEs buy only loans for amounts that are below these limits and that meet additional eligibility criteria, such as limits on debt-to-income ratios. ${ }^{29}$ During the 2003-2007 period the GSEs purchased 74.8 percent of all securitized loans in the conforming market, a number that rose to 98.7 percent in the postcrisis period. In contrast, virtually all loan purchases in the jumbo market were done by private securitizers. Analyzing the jumbo market separately provides an opportunity to see whether the rules used in screening mortgage borrowers, and their effect on securitization, are different in the absence of the GSEs. In the 2008-2009 sample there are few jumbo loans and few private-label purchases, so we do not analyze the jumbo market separately.

In addition to the conforming and jumbo samples, we examine the low-documentation ("lowdoc") and full-documentation ("full-doc") subgroups in order to provide additional comparability with KMSV's results. One feature of the recent mortgage boom was the proliferation of so-called low-doc loans, which unlike standard full-doc loans required limited or no documentation of borrowers' income and assets. ${ }^{30}$ KMSV restricts the main analysis to low-doc loans because, the authors argue, soft information plays a bigger role in screening these loans due to their lack of

\footnotetext{
${ }^{27}$ For the continental United States, the conforming loan limits for single-family homes were $\$ 322,700$ in 2003 , $\$ 333,700$ in 2004, $\$ 359,600$ in 2005, and $\$ 417,000$ in 2006 and 2007. Limits outside the continental U.S. were 50 percent higher. Beginning in 2008 conforming limits became more complex, with limits based on local cost-of-living calculations.

${ }^{28} \mathrm{KMSV} 2$ argues that pooling loans sold to private-label securitizers with loans sold to the GSEs in our conforming sample is inappropriate. The authors argue that there are two separate markets: (1) the "non-agency" market of loans only at risk of being purchased by private-label securitizers and not the GSEs; and (2) the "agency" market of loans only at risk of being purchased by the GSEs and not private-label securitizers. They assume that loans are either in one market or the other and that no loan is at risk of being bought by both private-label securitizers and the GSEs. As discussed below in Section 6.1, this assumption is inconsistent with the data, and estimation of the probability of securitization at a given FICO score requires pooling GSE-securitized loans, private-label-securitized loans, and portfolio loans.

${ }^{29}$ Although "non-jumbo" would technically be a more accurate term, for simplicity we use the term "conforming" for all loans that are for amounts below the conforming loan limits, including loans that fail to meet these other eligibility criteria.

${ }^{30}$ Our definition of "low-documentation" includes so-called "no-documentation" loans.
} 
hard information. Hence, they expect that securitization has a bigger effect on lender screening for low-doc loans than for full-doc loans.

However, the amount of documentation required by lenders is an important aspect of lender screening, which is the outcome variable of interest. Indeed, documentation status is a more direct measure of lender screening than is loan performance. Figure 7 plots the percentage of loans in our conforming sample that are classified as low-doc loans as a function of FICO score. Consistent with other evidence that lender screening changes at cutoffs such as 620 and 660, there are large jumps in the fraction of low-doc loans at 620 and 660. Accordingly, selecting the sample based on the outcome results in biased estimates of the effect of the change in market participants' behavior at 620 on loan performance - a problem referred to by statisticians as posttreatment selection bias (Frangakis and Rubin, 2002). Nonetheless, we include analysis of the low-doc and full-doc samples to provide better comparability with KMSV's results.

4.4. Econometric specifications and variable definitions. If lenders become discontinuously less strict right above a credit score cutoff, that should be manifested in jumps in the number of loans and their credit quality at the cutoff. To test for discontinuities in the number of loans at credit score thresholds, we follow McCrary (2008), which develops a formal test of the continuity of the density function of the running variable in RD analyses that allows for proper inference.

We use the default rate of loans as our measure of credit quality. We define default as being delinquent by 61 days or more. We use as long a follow-up period as possible in order to observe default. However, the observable follow-up period varies with origination vintage. Therefore, for each of our subgroups we use the longest follow-up period that is observable for all loans in the subsample. This means that for our 2003-2007 sample we define delinquency as a binary variable equal to 1 if payment was delinquent by 61 days or more at any time in the first 36 months after origination, and 0 otherwise. ${ }^{31}$ For our January 2008-June 2009 sample we are only able to employ an 18-month follow-up period.

We define securitization analogously as a binary variable equal to 1 if a loan is sold out of portfolio at any time during the loan's follow-up period. Our results are robust to alternate definitions of both default and securitization.

\footnotetext{
$\overline{{ }^{31} \text { We obtained }}$ our dataset in early 2011, when December 2010 was the most recent available month.
} 
To estimate discontinuities in the default rate and the securitization rate, we perform a standard RD analysis. For the 620 FICO cutoff, we estimate 6th-order polynomials on either side of the cutoff using the full sample:

$$
Y_{i}=\beta_{0}+\beta_{1} \mathbb{1}_{\left\{F I C O_{i} \geq 620\right\}}+f\left(F I C O_{i}\right)+\mathbb{1}_{\left\{F I C O_{i} \geq 620\right\}} * g\left(F I C O_{i}\right)+\epsilon_{i}
$$

where $i$ indexes individual loans, $Y_{i}$ indicates whether loan $i$ defaulted (or was securitized), and both $f\left(F I C O_{i}\right)$ and $g\left(F I C O_{i}\right)$ are 6th-order polynomials in $F I C O$. We use analogous specifications to estimate discontinuities at the FICO score of $660 .^{32}$

4.5. Summary statistics. Tables 1, 2, 3, and 4 provide sample sizes and summary statistics for our data. Although the conforming and jumbo samples are mutually exclusive, all loans in the low-doc sample appear also in either the conforming or the jumbo sample. Among conforming loans, 91 percent of the sample is securitized through either the GSEs or private securitizers. In the jumbo sample only 73 percent are securitized; of these, nearly all are privately securitized. ${ }^{33}$ In the 2003-2007 period approximately 13 percent of conforming loans became at least 61 days delinquent within 36 months of origination, though the rate was nearly twice that for borrowers in the neighborhood of 620 .

\subsection{Results.}

4.6.1. The pre-crisis period: 2003-2007. We begin with the subsample of mortgages originated in 2003-2007. The data show that originators used credit score cutoff rules to screen mortgage borrowers in this period. Figure 1 presents a histogram of loan originations by FICO score in 2003-2007. The graph is a step-wise function, with sharp, sizable increases in loan frequency at the FICO scores of 600, 620, 660, 680, and 700. Because the underlying distribution of FICO score is continuous in the population of potential borrowers (KMSV, p. 311), these discontinuities in the distribution of loans demonstrate that the lending rate itself (that is, the probability a potential borrower gets a loan) jumps at these cutoffs.

\footnotetext{
${ }^{32}$ Results are similar using a local linear regression in which the sample is restricted to a 10 FICO score point band on either side of the threshold (unreported for brevity).

${ }^{33}$ We use a flag provided in the LPS dataset to identify which loans are jumbo loans. In theory the GSEs should not buy any jumbo loans; either the 2 percent of our jumbo sample that were purchased by the GSEs are miscoded or the GSEs do not comply perfectly with the conforming loan limits.
} 
For the remainder of the paper we focus on the two lowest credit score cutoffs established in the GSEs' underwriting guidelines: 620 and 660 FICO. ${ }^{34}$ We focus on 620 because of its use in KMSV and the large size of the discontinuity at 620 . The cutoff at 660 is also informative about the competing cutoff rule theories since it features prominently in the GSEs' guidance letters. Evidence of a screening cutoff in the absence of a discontinuity in the securitization rate at 660 would provide further evidence that the GSEs' underwriting guidelines had a direct effect on lender behavior.

Table 5 presents estimates of the discontinuities in the lending rate, default rate, and securitization rate for the 2003-2007 conforming, jumbo, low-doc, and full-doc subgroups. Panel A shows that in the conforming sample there are statistically and economically significant jumps in both the number of loans and their default rate at 620 and 660, but no corresponding jumps in the securitization rate. The jumps in default rate are estimated at 3.3 percentage points on a base default frequency of 23.2 percent at 620 , and 2.1 percentage points on a base default frequency of 15.3 percent at $660 .{ }^{35}$ The jumps in the securitization rate at 620 and 660 are estimated at -0.6 and -0.2 percentage points, respectively. These jumps are not economically significant in terms of the change in lenders' incentives and are of the opposite sign from that predicted by the securitization rule-of-thumb theory. ${ }^{36}$ Figure 8 presents these results graphically in plots of loan frequency, default, and securitization by FICO scores.

Panel B of Table 5 and Figure 9 show a largely similar pattern in the jumbo market. There are significant jumps in the number of jumbo loans as well as their default rate. The number of loans roughly doubles at 620 - there are 1,530 loans in the sample with a FICO score of 619, compared with 3,238 loans in the sample with a FICO score of 620-and the size of the jump in number of loans at 660 is similar. We estimate default discontinuities of 3.4 and 3.2 percentage points at

\footnotetext{
${ }^{34}$ Jiang, Nelson, and Vytlacil (2010) also focuses on 620 and 660 using KMSV's RD research design.

${ }^{35}$ The data show that originators did price this increased default risk to some extent. For example, there is a 6.3 basis point jump at 620 in the interest rate that applies six months into the term of the loan (full regression table unreported for brevity). Results are similar when the discontinuity is estimated separately for fixed-rate and adjustablerate mortgages. Because hybrid adjustable-rate mortgages are still in their initial fixed rate period six months into the loan, we also estimated the discontinuity as the sum of the adjustable rate margin plus the value of the interest rate index at the time of origination and find a 5.2 basis point jump in interest rates. While these jumps may seem modest in comparison to the default rate jumps, the sizes are consistent with the bubble in housing prices causing lenders to underestimate the effect of their change in screening at 620 on the ultimate realized default rate.

${ }^{36}$ While we find little change in the securitization rate at 620 or 660 in these samples, KMSV2 raises the possibility that the time it takes originators to securitize a loan changes at credit score cutoffs. We investigated this possibility but found only minor discontinuities in the time it takes originators to sell their loans. We report our time-to-securitize results in full in our companion paper, Bubb and Kaufman (2011), and summarize them in Section 6.3 below.
} 
620 and 660, respectively. In contrast to the conforming sample, we do find a small jump in the securitization rate in the jumbo sample at 620, estimated at 2.0 percentage points from a base rate of 80.7 percent below 620. However, the scatter plot in Figure 9 shows no apparent discontinuity at 620 . At 660 there is no statistically significant discontinuity in the securitization rate.

Finally, Panels C and D show that the low-doc and full-doc subgroups exhibit patterns very similar to the conforming sample-jumps up in the number of loans and their default rate but small negative jumps in the securitization rate at 620 and 660. Figures 10 and 11 present these results graphically.

The existence of discontinuous changes in default and lending rates in the absence of a jump up in the securitization rate in these subgroups is inconsistent with the securitization rule-of-thumb theory. The evidence shows that lenders are following cutoff rules in screening at 620 and 660 despite the absence of an increase in the probability of securitization. This is consistent with the institutional evidence that shows that the GSEs directed lenders to adopt 620 and 660 FICO score cutoff rules. More formally, it is direct evidence of a failure of the exclusion restriction. Furthermore, the absence of securitization discontinuities in these samples implies a violation of the first identifying assumption: there is no first stage. But, importantly, the violation of the exclusion restriction that we document means that focusing on subgroups that do exhibit a first stage discontinuity in securitization would not make KMSV's research design valid. The discontinuous change in lender screening caused by the origination rule-of-thumb would confound any change in incentives due to a change in the probability of securitization at the credit score thresholds.

In contrast, these estimates are consistent with the origination rule-of-thumb theory. The jumps in default and number of loans at 620 and 660 show that lenders are following credit score cutoff rules in screening. The origination rule-of-thumb theory predicts that this discontinuous change in lender screening may induce a jump in the securitization rate much like the one we find in the jumbo market at 620 .

4.6.2. The post-crisis period: 2008-2009. Another way to investigate whether credit score cutoff rules are solely a product of a rule of thumb among private-label securitizers is to analyze a sample of loans originated in January 2008-June 2009, after the private-label market shut down. During the peak years of 2005 and 2006, private-label securitizers issued \$1,191 billion and \$1,146 billion 
of MBS, respectively. ${ }^{37}$ However, after the mass downgrades of private-label MBS by the rating agencies in 2007 that followed the onset of the subprime mortgage crisis, private-label MBS issuance ground to a halt. In 2007 only $\$ 707$ billion private-label MBS were issued, followed by a mere $\$ 58$ and $\$ 60$ billion in 2008 and 2009, respectively. Of these, only $\$ 2$ billion and $\$ 0.9$ billion, respectively, were subprime MBS. This is tiny relative to the $\$ 1,500$ billion and $\$ 1,800$ billion in mortgages originated in 2008 and 2009, respectively. If credit score cutoff rules in screening are a product of a rule of thumb among private-label securitizers, then there should be no credit score discontinuities in our sample of loans originated in 2008-2009.

The 2008-2009 sample had a very different price appreciation experience than the 2003-2007 sample, since its loans were originated after the bursting of the housing bubble. Moreover, we have a much shorter follow-up period available: we use whether the loan defaulted within 18 months of origination as our measure of loan performance. These differences should result in smaller measured jumps in default for the same jump in borrower creditworthiness than in the 2003-2007 sample. Our ability to observe jumps in lending volume is unchanged.

Figure 12 and Panel A of Table 6 show the discontinuities at 620 and 660 FICO in lending volume, default rate, and securitization rate for loans originated in 2008-2009. The data reveal that the cutoff rules in screening at 620 and 660 FICO persist in this period without private-label securitization. There are large jumps in the number of loans at each of these thresholds. As expected, the jumps in default are relatively small but still statistically significant. Securitization appears smooth through the cutoffs, with no statistically significant jump at 620 and a jump of only 0.7 percentage points at 660 .

During this period, loans insured by the Federal Housing Administration (FHA) and the Veterans Administration (VA) grew to become a substantial fraction of the mortgage market. FHA and VA loans constitute 33 percent of our 2008-2009 sample. The secondary market for FHA and VA loans is dominated by the Government National Mortgage Association (Ginnie Mae), a federal agency. Virtually all FHA and VA loans are bought by Ginnie Mae, so all are securitized. There should be no jump in the securitization rate at FICO 620 or 660 for these loans. This subgroup offers another way to test the securitization rule-of-thumb theory.

\footnotetext{
${ }^{37}$ These statistics are from the 2011 Mortgage Market Statistical Annual, published by Inside Mortgage Finance.
} 
Figure 13 and Panel B of Table 6 present the discontinuities in the subgroup of FHA / VA loans. In this subgroup too we see discontinuities in the number of loans and the default rate of loans at 620 and 660 but no corresponding changes in the probability of securitization. ${ }^{38}$ As expected, the plot of the securitization rate for this sample shows that virtually all of these loans are securitized.

These results provide more evidence against the identification assumption underlying the RD research design in KMSV. The data from 2008-2009 show that even when there is essentially no private-label securitization, and no discontinuity in securitization at these thresholds, lenders screen differentially across the 620 and 660 FICO thresholds. This is strong evidence that the 620 and 660 FICO score lender screening cutoff rules operate independently of a change in securitization.

4.6.3. Cohort analysis. We can extend our analysis of the 2008-2009 period by looking more generally at the size of the 620 cutoff for different cohorts of loans by origination year and comparing them to the size of the private-label MBS market over time. Private-label MBS issuance began as a small portion of the overall mortgage market. In 2004, however, its share began to increase rapidly, reaching 39 percent of the mortgage market in 2006, before collapsing to nearly nothing after 2008. If the 620 cutoff is caused solely by a purchasing rule of thumb used by private-label securitizers, as argued in KMSV2, we would expect to see the size of the discontinuity at 620 similarly rise and fall over this period.

Figure 15 shows the size of the discontinuity in $(\log )$ number of loans at 620 for these cohorts from 1997 to 2010, as well as the fraction of mortgages originated during each period that are bought by private-label securitizers. ${ }^{39}$ The proportion of mortgages bought by private-label securitizers follows a clear inverted U pattern. The 620 discontinuity, however, follows a very different pattern. It is positive though small in the period following the GSEs' original 1995 credit score

\footnotetext{
${ }^{38}$ The histogram reveals that at both 620 and 660, the number of loans is far greater than the number of loans at surrounding FICO scores - the markers at these two scores float above the rest of the markers in the figure. One potential explanation for this is that mortgage borrowers with lower credit scores wait until their scores reach these thresholdsand hence they are subject to less screening-before applying for loans. At 620, there is a clear discontinuity in the number of loans even ignoring the data right at 620 . In contrast, at 660 there is not a discontinuity if the loans right at 660 are ignored.

${ }^{39}$ The MBS data come from the Mortgage Market Statistical Annual, compiled by Inside Mortgage Finance. We are able to use origination data through December 2010 here because this application of the data does not require any follow-up period for observation of outcomes.
} 
cutoff rule guidelines, ${ }^{40}$ grows steadily throughout the boom in private-label mortgage securitization, and finally reaches its greatest size in the years 2009-2010, when the private-label market is nonexistent. This is further confirmation that the 620 discontinuity is not an artifact of private-label securitization. ${ }^{41}$

\section{USING VARIATION FROM ANTI-PREDATORY LENDING LAWS}

KMSV (pp. 341-344) explicitly considers our central hypothesis-that the 620 FICO score threshold was used by lenders for reasons unrelated to securitization — and attempts to test it by using variation induced by the passage of state anti-predatory lending laws in Georgia and New Jersey in 2002 and 2003, respectively. We examine this analysis here and conclude that the evidence is both consistent with the origination rule-of-thumb theory and inconsistent with the securitization rule-of-thumb theory.

The Georgia Fair Lending Act (GFLA) ${ }^{42}$ and the New Jersey Home Ownership Security Act $(\mathrm{NJHOSA})^{43}$ restricted a range of lending practices by mortgage originators and also made assignees of mortgages, such as securitizers, liable if the originator violated the laws' proscriptions. Both laws were later weakened by amendments. KMSV (p. 341) argues that the laws made it harder for lenders to securitize mortgages but kept "everything else equal." The authors argue that these laws provide a test of the origination rule-of-thumb theory, arguing that if originators use 620 as a "cutoff for screening unrelated to securitization, we expect the passage of these laws to have had no effect on the differential screening standards around the threshold" (p. 342). They argue that, in contrast, if the securitization rule-of-thumb theory is true and "these laws affect the differential ease of securitization around the [620] threshold ... the screening differentials [around 620] we observed earlier should attenuate" (p. 342).

\footnotetext{
${ }^{40}$ Pooling together the $1997-2000$ subgroup, the number of loans jumps by a statistically significant $.06 \log$ points at 620.

${ }^{41}$ KMSV2 (pp. 14-16) examines different cohorts of privately securitized loans in the LoanPerformance dataset and finds that variation across cohorts in the size of the jump in the default rate of securitized loans at 620 correlates with variation across cohorts in the size of the jump in the number of securitized loans at 620 . They argue that this corroborates their securitization rule-of-thumb theory. However, a time-series correlation between the size of jumps in the number of loans and in the default rate is equally consistent with the origination rule-of-thumb theory, and indeed with any theory that holds that jumps in the number of loans are driven by discontinuous lender screening intensity. When lenders reduce their screening intensity above 620, it both increases the number and lowers the credit quality of loans made above 620. Thus, the bigger the drop in screening intensity at 620 for a cohort of loans, the larger both the jump in the number of loans and the jump in default rates, ceteris paribus.

${ }^{42}$ O.C.G.A. $§ 7-6 \mathrm{~A}-1$, et seq.

${ }^{43}$ N.J.S.A. 46:10B-22, et seq.
} 
Using this approach, KMSV first shows that the jump in the number of low-doc private-label securitized loans at 620 is smaller for mortgages originated in the two states during the period the laws were in effect unamended than it is for mortgages originated before and after the laws. Second, surprisingly KMSV finds that there is no jump in the default rate of low-doc privatelysecuritized loans at 620 for loans originated in the two states before and after the laws. And the authors find that there is a jump in the default rate at 620 for loans originated in the two states when the laws were in effect, but that that jump is negative (KMSV, Table IV, p. 343). They argue that "taken together, these results suggest that our findings [of default discontinuities at 620] are indeed related to differential securitization at the credit threshold and that lenders were not blindly following the rule of thumb in all instances" (p. 344).

However, there are three problems with this analysis. First, the securitization rule-of-thumb theory does not predict the pattern in the data they found. Rather, their theory predicts that there should be a positive default discontinuity at 620 when the laws were not in effect, and no default discontinuity at 620 when the laws were in effect. ${ }^{44}$ KMSV's finding that a 620 rule of thumb operated during the period in which they argue securitization was inhibited thus undercuts the securitization rule-of-thumb theory.

Second, KMSV's claim that the laws changed only ease of securitization, and that therefore the laws would have no direct effect on the size of the discontinuity in default at 620 , is inconsistent with the content of the laws. The goal of the NJHOSA was to prevent abusive lending practices. In addition to enabling borrowers to assert any claims against the purchaser of their mortgage that they could have asserted against the originating lender (that is, creating "assignee liability"), it restricted a range of lending practices, including certain kinds of lender-financed insurance, loan "flipping," and late payment fees. Furthermore, for a class of "high-cost" loans, the Act limited the rate at which scheduled payments could increase on adjustable rate mortgages, negative amortization, interest rate increases upon default, and the financing of points and fees. The GFLA contained similar provisions targeting a range of abusive lending practices. ${ }^{45}$ Furthermore, the GFLA prohibits lenders from making certain high-cost loans unless the borrower has received

\footnotetext{
${ }^{44}$ One possible source of confusion is that, under the predictions of KMSV's theory, the coefficient on the interaction between the law and the default discontinuity is negative. In KMSV's actual results the interaction is negative as well. However, a positive jump that goes to zero under the law and a zero jump that becomes negative under the law are not equivalent. The former is consistent with the securitization rule-of-thumb theory while the latter is not.

${ }^{45}$ O.C.G.A. $\S 7-6 \mathrm{~A}-1$, et seq.
} 
counseling on the advisability of the loan and the lender reasonably believed that the borrower would be able to make the payments on the loan. ${ }^{46}$ One of the express purposes of these provisions was to reduce default.

These restrictions can be expected to change the lending rate and default rate discontinuities at 620 through channels other than securitization. The laws were designed to lower default levels directly. And because there are more high default risk loans above 620, the laws can be expected to have a bigger effect on default above 620. Regressions (not reported for brevity ${ }^{47}$ ) also confirm statistically significant discontinuities around 620 in contract terms such as LTV, debt-to-income ratio, prepayment penalties, interest-only loans, and negative amortization, all of which further reinforce that the laws could affect loans above the threshold differently from loans below. Jiang, Nelson, and Vytlacil (2010) also find discontinuities in contract terms at 620 using data from a single large originator. Given the content of the laws and their potential to affect lending through channels other than securitization, they do not provide a valid test of the origination rule-of-thumb theory.

Third, because the authors use a dataset containing only securitized loans, they cannot confirm that the laws in fact lowered the rate of securitization. KMSV (p. 343) shows that the discontinuity in the number of low-doc, private-label securitized loans at 620 fell when the laws were in effect. However, that finding is consistent with the origination rule-of-thumb theory. Provisions of the laws, such as the GFLA's requirement that lenders reasonably believe the borrower would be able to make the payments on the loan, can be expected to reduce the discontinuity in the number of low-doc loans. In this section we estimate the effect of the laws on the securitization rate using the LPS data and show that, contrary to the assumptions in KMSV, these laws did not lower the rate of securitization. Because the laws did not actually lower the rate of securitization, examining the size of discontinuities in default during the law changes cannot be informative about the effects of securitization.

Shortly after they were passed, both laws were amended to weaken their restrictions. The amendment to the GFLA limited the relief that could be granted against an assignee, and the amendment to the NJHOSA provided that borrowers could seek relief under the act only in their individual capacity and not as part of a class action. We define the period when each law was in

$\overline{{ }^{46} \text { O.C.G.A. } \S 7}-6 A-5$ (6)-(7).

${ }^{47}$ We provide the results in Bubb and Kaufman (2011). 
effect as the interval between the date when it initially took effect and the date its amendment took effect. These are from the start of October 2002 to the end of February 2003 for the GFLA, and between the start of December 2003 and the end of May 2004 for the NJHOSA.

We use a difference-in-differences (DD) strategy to estimate the effect of each law on securitization. In order to make the requisite parallel trends assumptions more plausible, we use as comparison groups for each state the states that border them, and restrict the dataset to the period from six months before each law was passed to six months after it was amended. ${ }^{48}$ To maximize the sample size, we pool conforming and jumbo loans. For Georgia, with the sample restricted to contain loans originated in Georgia and its comparison group during the appropriate time window, we estimate:

$$
Y_{i}=\delta_{0}+\delta_{1} G A_{i}+\delta_{2} \text { LawPeriod }_{i}+\delta_{3} \text { Law }_{i}+\epsilon_{i},
$$

where $Y_{i}$ is a securitization dummy, $G A_{i}$ is an indicator of whether loan $i$ was originated in Georgia, LawPeriod $_{i}$ is an indicator of whether the loan was originated during the period when the GFLA was in effect but not yet amended, and $L a w_{i}$ is the interaction of $G A_{i}$ and LawPeriod $_{i}$. We thus pool the pre-law and post-amendment periods together as the control period. We estimate the analogous specification for New Jersey separately.

Table 7 shows results for the two law changes. For Georgia, the DD estimate of the effect of the law is an insignificant 0.3 percentage point increase in securitization. For New Jersey, the effect is a signficant 0.5 percentage point increase. Our data thus show that the laws did not have a negative effect on the securitization rate. Because the New Jersey and Georgia laws may have affected default rates directly, and because the laws do not appear to have lowered securitization rates, analysis of these laws cannot be used as evidence against our thesis that lenders employed credit score cutoff rules for reasons unrelated to the probability of securitization.

\section{FURTHER ARGUMENTS MADE IN KMSV2}

KMSV2 is a response to an earlier version of this paper in which the authors of KMSV make a set of additional arguments in favor of the securitization rule-of-thumb theory. We respond to these arguments in detail in a companion piece, Bubb and Kaufman (2011), the main points of which we summarize here.

\footnotetext{
${ }^{48}$ Specifically, the bordering states are DE, NY, and PA for NJ; and AL, FL, NC, SC, and TN for GA.
} 
6.1. Separate markets assumption. KMSV2 argues that our approach of pooling loans sold to private-label securitizers with loans sold to the GSEs in our conforming sample is inappropriate. The authors argue that there are two separate markets: (1) the "non-agency market" of loans only at risk of being purchased by private-label securitizers and not the GSEs (which they also refer to as the "subprime" market); and (2) the "agency market" of loans only at risk of being purchased by the GSEs and not by private-label securitizers (which they also refer to as the "prime" market). They assume that loans are either in one market or the other and that no loan is simultaneously at risk of being bought by private-label securitizers and by the GSEs. Moreover, they argue that the 620 FICO rule of thumb was used only by private-label securitizers and not by the GSEs, and only for low-doc loans, not for full-doc loans (KMSV2, p. 9).

However, the evidence is inconsistent with this separate markets assumption. We look to the data and find that 18 percent of loans in our 2003-2007 conforming sample were at one point owned by the GSEs and at another point owned by private-label securitizers. This is only a lower-bound on the overlap between the two types of purchasers-many loans that were ex ante simultaneously at risk of being bought by both were ex post held by only one type of buyer. Moreover, institutional evidence shows that the GSEs and private-label securitizers actively competed over subprime loans in the secondary market during this period. The fact that loans were at risk of being sold to both GSEs and private-label securitizers implies that GSE loans and private-label securitized loans, as well as portfolio loans, must be pooled together in order to correctly estimate the probability of securitization at any given FICO score.

We furthermore show that discontinuities in the lending rate and the default rate exist for loans other than low-doc private-label securitized loans. We show that even when we examine only loans that were owned by the GSEs, as well as full-doc loans owned by the GSEs, the discontinuities are still evident. ${ }^{49}$ Similarly, as shown above, the lender cutoff rules in screening persist in 2008-2009, after the private-label market had shut down. Finally, note that we see a discontinuity in default in the absence of a discontinuity in the probability of securitization in our jumbo sample, which is an exclusively non-agency market.

6.2. Measuring ease of securitization. KMSV2 (pp. 19-21) considers different aspects of what the authors refer to as "ease of securitization" and argues that the number of securitized loans at

\footnotetext{
${ }^{49}$ This result contradicts KMSV2's finding of no discontinuity among GSE-securitized loans. We are unaware of any reason for the discrepancy. When asked, the authors did not provide us with the code they used to generate their result.
} 
a FICO score is a better measure of ease of securitization for loans at that FICO score than is the fraction of loans that are securitized (that is, the securitization rate) at that FICO score because it “is likely to capture the complete impact" of securitization on lenders' payoffs (p. 21).

However, as we explained above in Section 4.2, the jump in the number of securitized loans at a credit score cutoff cannot be used as a measure of the change in lenders' incentives due to securitization at the cutoff because it confounds changes in the lending rate and changes in the securitization rate.

To illustrate the problem with using the total number of securitized loans rather than the securitization rate as a measure of ease of securitization, we offer a thought experiment: suppose we were investigating the opposite hypothesis from KMSV, namely that a lack of securitization-that is, lenders' having to keep loans in portfolio—causes lax screening. Applying KMSV's approach to test this hypothesis, we would use the number of portfolio loans as a measure of the risk lenders get stuck with loans. If we find jumps in the number of portfolio loans and their default rate at a threshold like 620, we would interpret that as evidence that skin in the game ruins lenders' incentives.

We can use the LPS dataset to actually implement this research design. We mimic KMSV's approach by restricting our dataset to only unsecuritized (portfolio) loans, and we test whether increases in the number of unsecuritized loans are associated with jumps in the default rate. We estimate a jump in the number of unsecuritized loans at 620 of $0.342 \log$ points, and a jump in the default rate of those loans of 6.5 percentage points. Figure 14 panels (a) and (d) show these jumps graphically, alongside similar panels for GSE securitized and private-label securitized loans from the same origination years.

Interpreted using KMSV's approach, we have provided evidence that a lack of securitization led to lax underwriting and contributed to the financial crisis. The problem with this interpretation of the jump in portfolio loans at 620 is that lenders changed their overall lending rate at this cutoff. This can be seen in the jumps in the number of private-label securitized loans and GSE securitized loans from the same origination years, also displayed in Figure 14.

6.3. Time to securitize. KMSV2 raises the possibility that the time it takes originators to securitize a loan changes at credit score cutoffs. Using the same RD methodology as before, we estimate the change in the number of months securitized loans are on the books of the originator before 
being sold at 620 and 660 . We find that there are only minor discontinuities in the time it takes originators to sell their loans. For example, at the 620 threshold in our 2003-2007 conforming sample, our point estimate is an insignificant difference of 0.003 months. Hence, a discontinuity in time to securitize does not explain the large change in lender screening at 620 that we document in our data. ${ }^{50}$ Our largest estimate is for jumbo loans at 620. There we find that loans above 620 take 0.713 fewer months for originators to sell than loans below 620. Only 0.63 percent of loans near the cutoff in that sample default in that additional 0.713 of a month, out of a total default rate of 31.2 percent. All other samples exhibit smaller or nonexistent discontinuities in time to securitize (see Bubb and Kaufman (2011) for full results).

KMSV2 also suggests that the prevalence of buybacks (loans that default shortly after being sold and that the originator is forced to buy back) changes around the cutoff, and that this is best captured by using the unconditional lending rate. We estimate the prevalence of buybacks directly, and show that their prevalence does not change around the 620 and 660 cutoffs.

\section{CONCLUSION}

In this paper we argue that lenders adopted credit score cutoff rules directly in response to underwriting guidelines from Fannie Mae and Freddie Mac. Institutional evidence shows that the GSEs required lenders to adopt credit score cutoff rules and that these rules spread through their incorporation into underwriting software. Moreover, we develop a simple equilibrium model that rationalizes the use of such cutoff rules in origination. Evidence from a loan-level dataset shows that there are screening cutoffs at 620 and 660 in the absence of a discontinuous increase in securitization. The data show that these lender screening cutoffs persisted in 2008-2009, after the private-label mortgage securitization market had shut down.

This pattern of evidence is consistent with the origination rule-of-thumb theory but not the securitization rule-of-thumb theory. This implies that credit score cutoff rules unfortunately do not provide a useful laboratory for estimating the effect of securitization on lender screening. Lenders

\footnotetext{
${ }^{50}$ Our estimates are much smaller than the 1.9 month change in time-to-securitize for low-doc private-label securitized loans reported in KMSV2. We tried to replicate KMSV2's estimate using their 2001-2006, low-doc, private-label securitized sample, but we estimated a 0.61 month change using that sample. We inquired with the authors of KMSV2 about this discrepancy, and they reported that they had made a mistake in reporting their point estimate and that the correct point estimate is 1.1 months, about half as large as the estimate reported in KMSV2 and closer to our 0.61 month estimate. We requested from the authors of KMSV2 the code they used to generate their estimates, but they did not provide it.
} 
change their screening behavior at the credit score cutoffs for reasons other than a change in the probability of securitization. Therefore the change in default at these credit score cutoffs is not evidence that securitization led to lax screening by lenders.

The cutoff rule evidence does tell us, however, that Fannie Mae and Freddie Mac were to a significant extent successful in implementing their desired underwriting guidelines throughout the mortgage industry. After concluding that credit score cutoff rules in screening would improve mortgage underwriting, Fannie and Freddie used contractual provisions, monitoring, and software systems to ensure that originators adopted them. This evidence, of course, does not settle the important question of the extent to which securitization led to lax underwriting in the run-up to the subprime mortgage crisis. It remains an open and pressing research question.

\section{REFERENCES}

Adelino, M., K. Gerardi, And P. Willen (2009): “Why Don't Lenders Renegotiate More Home Mortgages? Redefaults, Self-Cures, and Securitization," NBER Working Paper 15159.

AKERLOF, G. (1970): "The Market for Lemons: Quality Uncertainty and the Market Mechanism," The Quarterly Journal of Economics, 84(3), 488-500.

Avery, R., R. Bostic, P. Calem, And G. CAnner (1996): “Credit Risk, Credit Scoring, and the Performance of Home Mortgages," Federal Reserve Bulletin, 82(7), 621-648.

BAUMOL, W. J., AND R. E. QUANDT (1964): "Rules of Thumb and Optimally Imperfect Decisions," American Economic Review, 54(3), 44-52.

BubB, R., AND A. KAUfMAN (2009): "Securitization and Moral Hazard: Evidence from a Lender Cutoff Rule," Federal Reserve Bank of Boston Public Policy Discussion Paper No. 09-5.

(2011): "Further investigations into the origin of credit score cutoff rules," Unpublished manuscript.

Cassidy, H., And R. Englestad (1998): "Credit Scoring and the Secondary Market: Perceptions, Policies, Practices," Community Investments, 10(3).

Comptroller of THE CURRency (1997): “Asset Securitization: Comptroller's Handbook,” .

Demiroglu, C., And C. JAMES (2011): "Works of Friction? Originator-Sponsor Affiliation and Losses on Mortgage Backed Securities," Unpublished manuscript.

DEMyANyK, Y., AND O. VAn Hemert (2009): "Understanding the Subprime Mortgage Crisis," Review of Financial Studies, 22.

Downing, C., R. Jaffee, And N. Wallace (2009): "Is the Market for Mortgage Backed Securities a Market for Lemons?," Review of Financial Studies, 22(7).

Drucker, S., AND M. PuRi (2008): “On Loan Sales, Loan Contracting, and Lending Relationships," Review of Financial Studies, 22(7).

Ellison, G., And R. Holden (2008): “A Theory of Rule Development,” Unpublished manuscript.

EluL, R. (2009): “Securitization and Mortgage Default: Repuation vs. Adverse Selection,” Unpublished manuscript. 
FAnNiE Mae (1995): "LL09-95: Measuring Credit Risk: Borrower Credit Scores and Lender Profiles," Letter to lenders.

(1997): "LL01-97: Mortgage Underwriting Tools-Automated Underwriting and Credit Scores: Measuring Credit Risk: Borrower Credit Scores and Lender Profiles," Letter to lenders. (2007): "Guide to Underwriting with DU," Letter to Lenders. (2011): "Selling Guide: Fannie Mae Single Family," .

FRAnGakis, C. E., AND D. B. RUbin (2002): "Principal Stratification in Causal Inference," Biometrics, 58(1), 21-29.

FREDdIE MAC (1995): “The Predictive Power of Selected Credit Scores,” Industry Letter. (2001): "Single-Family Seller/Servicers Guide," Guidebook for Lenders.

Gerardi, K., A. Shapiro, and P. Willen (2007): "Subprime Outcomes: Risky Mortgages, Homeownership Experiences, and Foreclosures," Federal Reserve Public Policy Discussion Paper No. 07-15.

Gorton, G. (2009): “The Subprime Panic,” European Financial Management, 15(1), 10-46.

Gorton, G., And G. Pennacchi (1995): "Banks and Loan Sales Marketing Nonmarketable Assets," Journal of Monetary Economics, 35(3), 389-411.

Hutto, G., And J. Lederman (2003): Handbook of Mortgage Lending. Mortgage Bankers Association of America.

IMBENS, G., AND T. LEMIEUX (2008): "Regression discontinuity designs: A guide to practice," Journal of Econometrics, 142(2), 615-635.

Jiang, W., A. Nelson, And E. Vytlacil (2009): "Liar's Loan? Effects of Loan Origination Channel and Loan Sale on Delinquency," Unpublished manuscript.

- (2010): "Securitization and Loan Performance: A Contrast of Ex Ante and Ex Post Relations in the Mortgage Market," Unpublished manuscript.

Keys, B., T. MukherJee, A. Seru, And V. Vig (2009): "Financial regulation and securitization: Evidence from subprime loans," Journal of Monetary Economics, 56(5), 700-720.

Keys, B., T. MukherjeE, A. Seru, And V. Vig (2010a): “620 FICO, Take II: Securitization and Screening in the Subprime Mortgage Market," Unpublished manuscript.

Keys, B., T. Mukherjee, A. Seru, and V. Vig (2010b): "Did Securitization Lead to Lax Screening? Evidence from Subprime Loans," Quarterly Journal of Economics, 125(1).

KEys, B., A. SERU, AND V. VIG (2011): "Lender Screening and the Role of Securitization: Evidence from Prime and Subprime Mortgage Markets," Review of Financial Studies, forthcoming.

Krainer, J., AND E. LAdERMAN (2009): "Mortgage Loan Securitization and Relative Loan Performance," Unpublished manuscript.

MAyer, C., K. Pence, And S. Sherlund (2009): “The Rise in Mortgage Defaults,” Journal of Economic Perspectives, 23(1), 27-50.

MCCRARY, J. (2008): "Manipulation of the Running Variable in the Regression Discontinuity Design: A Density Test," Journal of Econometrics, 142(2), 698-714.

Mian, A., AND A. Sufi (2009): “The Consequences of Mortgage Credit Expansion: Evidence from The U.S. Mortgage Default Crisis Stability," The Quarterly Journal of Economics, 124(4).

PennacCHI, G. (1988): "Loan Sales and the Cost of Bank Capital," Journal of Finance, 43(2), 375-396.

PISKORSKI, T., A. SERU, AND V. Vig (2008): "Securitization and Distressed Loan Renegotiation: Evidence from the Subprime Mortgage Crisis," Unpublished manuscript. 
Poon, M. (2009): "From new deal institutions to capital markets: Commercial consumer risk scores and the making of subprime mortgage finance," Accounting, Organizations, and Society, $34,654-674$.

Quinn, L. (2000): “Credit Score Scrutiny,” Mortgage Banking, 60(12), 50-55.

RajAn, U., A. SERU, And V. VIG (2010): “The Failure of Models That Predict Failure: Distance, Incentives and Defaults," Unpublished manuscript.

STRAKA, J. W. (2000): "A Shift in the Mortgage Landscape: The 1990s Move to Automated Credit Evaluations," Journal of Housing Research, 11(2), 207-232.

SuFI, A. (2007): "Information Asymmetry and Financing Arrangements: Evidence from Syndicated Loans," The Journal of Finance, 62(2), 629-668.

Washington Mutual Home Loans (2006): "Mortgage Securities Corporation Seller Guide," Internal manual.

\section{APPENDIX A}

Proof of Proposition 1. For each loan applicant type $x$, the lender does one of three things: denies the applications, accepts the applications without investigation, or investigates each applicant and, if no defaulter signal is observed, accepts the application. Denote this choice as $a \in\{D, A, I\}$. The per-applicant payoff to the lender of each of these actions for each value of $x$ is given by:

$$
V(x \mid a)= \begin{cases}0 & \text { if } a=D \\ \bar{R} x-1 & \text { if } a=A \\ (1-(1-x) s)\left(\frac{x}{1-(1-x) s} \bar{R}-1\right)-c & \text { if } a=I .\end{cases}
$$

The lender's optimization problem is thus to choose an action $a(x)$ for each value of $x$ that solves:

$$
\max _{a \in\{D, A, I\}}\{V(x \mid a)\} \text {. }
$$

Accepting is preferred to investigating if and only if $\bar{R} x-1 \geq \bar{R} x-(1-(1-x) s)-c \Leftrightarrow$ $x \geq 1-\frac{c}{s}=\bar{x}$. Accepting is preferred to rejecting if and only if $\bar{R} x-1 \geq 0 \Leftrightarrow x \geq \frac{1}{\bar{R}}$. Investigating is preferred to rejecting if and only if $\bar{R} x-(1-(1-x) s)-c \geq 0 \Leftrightarrow x \geq \frac{1-s+c}{\bar{R}-s}=\underline{x}$. Hence, the proposition holds if and only if the following are true:

(1) $\bar{x}>\underline{x}$, or $1-\frac{c}{s}>\frac{1-s+c}{\bar{R}-s}$. Rearranging this inequality yields $c<\frac{(\bar{R}-1) s}{\bar{R}}$, which we assumed was true.

(2) $\bar{x}<1$, or $1-\frac{c}{s}<1$, which is true since $c>0$ and $s>0$.

(3) $\underline{x}>0$, or $\frac{1-s+c}{\bar{R}-s}>0$, which is true since $\bar{R}-s>0$ and $s-c<1$. 


\section{APPENDIX B}

TABLE 1. Sample Sizes

\begin{tabular}{r|c|cccc}
\hline \hline & Total & Conforming & Jumbo & Low-doc & Full-doc \\
\hline 2003 & $2,106,974$ & $1,977,965$ & 129,009 & 754,862 & 244,672 \\
2004 & $2,712,677$ & $2,371,601$ & 341,076 & $1,299,459$ & 496,093 \\
2005 & $3,531,579$ & $3,008,614$ & 522,965 & $1,565,218$ & 698,085 \\
2006 & $3,230,989$ & $2,868,342$ & 362,647 & $1,329,786$ & 730,844 \\
2007 & $2,915,924$ & $2,649,413$ & 266,511 & $1,453,095$ & 621,292 \\
2008 & $2,103,962$ & $2,039,782$ & 64,180 & $1,229,176$ & 394,356 \\
$2009 H 1$ & $1,333,948$ & $1,288,075$ & 45,873 & 873,704 & 226,072 \\
\hline All Years & $17,936,053$ & $16,203,792$ & $1,732,261$ & $8,505,300$ & $3,411,414$ \\
\hline
\end{tabular}

TABLE 2. Summary Statistics: 2003-2007 Conforming and Jumbo Samples

\begin{tabular}{r|ccc|ccc}
\hline \hline & \multicolumn{3}{|c|}{ Conforming } & \multicolumn{3}{c}{ Jumbo } \\
& Mean & S.D. & $N$ & Mean & $S . D$. & $N$ \\
\hline GSE Securitized & .683 & .463 & $12,875,935$ & .020 & .140 & $1,622,208$ \\
Private Securitized & .231 & .421 & $12,875,935$ & .712 & .453 & $1,622,208$ \\
Portfolio & .087 & .281 & $12,875,935$ & .268 & .443 & $1,622,208$ \\
Low-doc & .284 & .451 & $8,210,433$ & .463 & .499 & 982,973 \\
Adjustable & .246 & .430 & $12,778,436$ & .663 & .473 & $1,609,472$ \\
Refi & .545 & .498 & $12,875,935$ & .550 & .497 & $1,622,208$ \\
FHA/VA & .078 & .268 & $12,875,935$ & 0 & .019 & $1,622,208$ \\
Borrower FICO & 696.4 & 66.4 & $12,875,935$ & 716.6 & 53.2 & $1,622,208$ \\
Loan Amount (\$) & 195,463 & 95,151 & $12,875,852$ & 654,895 & 403,738 & $1,622,208$ \\
Loan-to-Value & 74.3 & 17.8 & $12,726,465$ & 72.2 & 12.3 & $1,611,602$ \\
Defaulted36 & .127 & .332 & $12,875,935$ & .154 & .361 & $1,622,208$ \\
Defaulted18 & .050 & .218 & $12,875,935$ & .054 & .225 & $1,622,208$ \\
\hline
\end{tabular}

Notes: Sample includes first-lien, non-buydown, owner-occupied, single-family mortgage loans originated in 2003-2007. GSE Securitized, Private Securitized, and Portfolio capture securitization status 6 months after origination. Low-doc includes both "low" and "no" documentation loans. Loan Amount in 2009 dollars. Defaulted36 equals 1 if loan became 61 days or more overdue within 36 months of origination. Defaulted 18 uses an 18-month follow-up. 
TABLE 3. Summary Statistics: 2003-2007 Low-Doc and Full-Doc Samples

\begin{tabular}{r|ccc|ccc}
\hline \hline & \multicolumn{3}{|c|}{ Low-doc } & \multicolumn{3}{c}{ Full-doc } \\
& Mean & $S . D$. & $N$ & Mean & S.D. & $N$ \\
\hline GSE Securitized & .585 & .493 & $2,790,986$ & .632 & .482 & $6,402,420$ \\
Private Securitized & .269 & .444 & $2,790,986$ & .262 & .440 & $6,402,420$ \\
Portfolio & .146 & .353 & $2,790,986$ & .106 & .308 & $6,402,420$ \\
Jumbo & .163 & .370 & $2,790,986$ & .082 & .275 & $6,402,420$ \\
Adjustable & .402 & .490 & $2,786,987$ & .243 & .429 & $6,376,281$ \\
Refi & .576 & .494 & $2,790,986$ & .577 & .494 & $6,402,420$ \\
FHA/VA & .060 & .237 & $2,790,986$ & .074 & .261 & $6,402,420$ \\
Borrower FICO & 699.2 & 59.0 & $2,790,986$ & 693.4 & 69.3 & $6,402,420$ \\
Loan Amount (\$) & 289,014 & 264,732 & $2,790,986$ & 225,818 & 198,943 & $6,402,420$ \\
Loan-to-Value & 73.0 & 16.9 & $2,769,400$ & 74.3 & 18.0 & $6,332,129$ \\
Defaulted36 & .158 & .365 & $2,790,986$ & .121 & .326 & $6,402,420$ \\
Defaulted18 & .057 & .232 & $2,790,986$ & .051 & .219 & $6,402,420$ \\
\hline
\end{tabular}

Notes: Sample includes first-lien, non-buydown, owner-occupied, single-family mortgage loans originated in 2003-2007. GSE Securitized, Private Securitized, and Portfolio capture securitization status 6 months after origination. Low-doc includes both "low" and "no" documentation loans. Loan Amount in 2009 dollars. Defaulted 36 equal to 1 if loan became 61 days or more overdue within 36 months of origination. Defaulted 18 uses an 18-month follow-up.

TABLE 4. Summary Statistics: 2008-2009

\begin{tabular}{r|ccc}
\hline \hline & Mean & $S . D$. & $N$ \\
\hline GSE Securitized & .946 & .227 & $3,437,910$ \\
Private Securitized & .013 & .115 & $3,437,910$ \\
Portfolio & .041 & .198 & $3,437,910$ \\
Jumbo & .032 & .176 & $3,437,910$ \\
Low-doc & .228 & .419 & $2,723,308$ \\
Adjustable & .036 & .185 & $3,435,707$ \\
Refi & .589 & .492 & $3,437,910$ \\
FHA/VA & .327 & .469 & $3,437,910$ \\
Borrower FICO & 716.0 & 61.7 & $3,437,910$ \\
Loan Amount (\$) & 212,685 & 143,725 & $3,437,908$ \\
Loan-to-Value & 77.3 & 19.1 & $3,388,371$ \\
Defaulted18 & .046 & .210 & $3,437,910$ \\
\hline
\end{tabular}

Notes: Sample includes first-lien, non-buydown, owner-occupied, single-family mortgage loans originated in Jan. 2008-June 2009. GSE Securitized, Private Securitized, and Portfolio capture securitization status 6 months after origination. Low-doc includes both "low" and "no" documentation loans. Loan Amount in 2009 dollars. Defaulted 18 equal to 1 if loan became 61 days or more overdue within 18 months of origination. 
TABle 5. Discontinuities in Pre-Crisis 2003-2007 Sample

\begin{tabular}{|c|c|c|c|c|c|c|}
\hline & \multicolumn{3}{|c|}{ FICO 620} & \multicolumn{3}{|c|}{ FICO 660} \\
\hline & $\begin{array}{c}\log (\# \text { loans }) \\
\text { (1) }\end{array}$ & $\begin{array}{l}\text { Default } \\
\text { (2) }\end{array}$ & $\begin{array}{c}\text { Securitization } \\
\text { (3) }\end{array}$ & $\begin{array}{c}\log (\# \text { loans }) \\
\text { (4) }\end{array}$ & $\begin{array}{l}\text { Default } \\
\quad(5)\end{array}$ & $\begin{array}{c}\text { Securitization } \\
\text { (6) }\end{array}$ \\
\hline \multicolumn{7}{|c|}{ PANEL A: CONFORMING LOANS $(N=12,875,935)$} \\
\hline Change at cutoff & $.307 * * *$ & $.033 * * *$ & $-.006 * * *$ & $.102 * * *$ & $.021 * * *$ & $-.002 * * *$ \\
\hline & $(.003)$ & $(.002)$ & $(.001)$ & $(.003)$ & $(.001)$ & $(.001)$ \\
\hline Predicted below & - & .232 & .935 & - & .153 & .934 \\
\hline \multicolumn{7}{|c|}{ PANEL B: JUMBO LOANS $(N=1,622,208)$} \\
\hline Change at cutoff & $.609 * * *$ & $.034 * * *$ & $.020 * *$ & $.307 * * *$ & $.033 * * *$ & .006 \\
\hline s.e. & $(.012)$ & $(.010)$ & $(.008)$ & $(.008)$ & $(.005)$ & $(.005)$ \\
\hline Predicted below & - & .312 & .807 & - & .247 & .791 \\
\hline \multicolumn{7}{|c|}{ PANEL C: LOW-DOC LOANS $(N=2,790,986)$} \\
\hline Change at cutoff & $.432 * * *$ & $.079 * * *$ & $-.009 * * *$ & $.141 * * *$ & $.039 * * *$ & $-.006 * *$ \\
\hline s.e. & $(.007)$ & $(.005)$ & $(.003)$ & $(.005)$ & $(.003)$ & $(.002)$ \\
\hline Predicted below & - & .224 & .917 & - & .193 & .894 \\
\hline \multicolumn{7}{|c|}{ PANEL D: FULL-DOC LOANS $(N=6,402,420)$} \\
\hline Change at cutoff & $.289 * * *$ & $.009 * * *$ & $-.004 * *$ & $.087 * * *$ & $.009 * * *$ & $-.006 * * *$ \\
\hline s.e. & $(.004)$ & $(.003)$ & $(.002)$ & $(.004)$ & $(.002)$ & $(.001)$ \\
\hline Predicted below & - & .252 & .934 & - & .143 & .923 \\
\hline \multicolumn{7}{|c|}{$\begin{array}{l}\text { Notes: Sample is loans originated in January } 2003-\text { December } 2007 \text {. Conforming loans include all } \\
\text { loans for amounts below the GSEs' conforming loan limits. Default is an indicator for whether } \\
\text { the loan ever became } 61 \text { days delinquent within } 36 \text { months of origination. Securitization is an } \\
\text { indicator for whether the loan was ever sold within } 36 \text { months of origination. Columns } 1 \text { and } 4 \\
\text { use a local linear regression, as outlined in McCrary }(2008) \text {. Columns } 2,3,5 \text {, and } 6 \text { fit a } 6 \text { th-order } \\
\text { polynomial in FICO on either side of the cutoff. Numbers of observations in Panels C and D do not } \\
\text { sum to the number of observations in Panel A because documentation status is missing for some } \\
\text { loans. Heteroskedasticity-robust standard errors in parentheses. }(* * *) \text { significant at } 1 \text { percent, }(* *) \\
\text { significant at } 5 \text { percent, }(*) \text { significant at } 10 \text { percent. }\end{array}$} \\
\hline
\end{tabular}


TABle 6. Discontinuities in Post-Crisis 2008-2009 Sample

\begin{tabular}{|c|c|c|c|c|c|c|}
\hline & \multicolumn{3}{|c|}{ FICO 620} & \multicolumn{3}{|c|}{ FICO 660} \\
\hline & $\begin{array}{c}\log (\# \text { loans }) \\
\text { (1) }\end{array}$ & $\begin{array}{l}\text { Default } \\
\text { (2) }\end{array}$ & $\begin{array}{c}\text { Securitization } \\
\text { (3) }\end{array}$ & $\begin{array}{c}\log (\# \text { loans }) \\
(4)\end{array}$ & $\begin{array}{l}\text { Default } \\
\text { (5) }\end{array}$ & $\begin{array}{c}\text { Securitization } \\
\text { (6) }\end{array}$ \\
\hline \multicolumn{7}{|c|}{ PANEL A: AlL LOANS $(N=3,437,910)$} \\
\hline Change at cutoff & $.372 * * *$ & $.007 *$ & .002 & $.210 * * *$ & $.018 * * *$ & $.007 * * *$ \\
\hline s.e. & $(.006)$ & $(.004)$ & $(.002)$ & $(.005)$ & $(.002)$ & $(.001)$ \\
\hline Predicted below & - & .134 & .974 & - & .071 & .966 \\
\hline \multicolumn{7}{|c|}{ PANEL B: FHA/VA LOANS $(N=1,123,381)$} \\
\hline Change at cutoff & $.338 * * *$ & $.009 * *$ & .001 & $196 * * *$ & $.024 * * *$ & -.000 \\
\hline s.e. & $(.007)$ & $(.004)$ & $(.000)$ & $(.006)$ & $(.003)$ & $(.000)$ \\
\hline Predicted below & - & .134 & .999 & - & .0721 & 1.000 \\
\hline
\end{tabular}

Notes: Sample is loans originated in January 2008-June 2009. Default is an indicator for whether the loan ever became 61 days delinquent within 18 months of origination. Securitization is an indicator for whether the loan was ever sold within 18 months of origination. Columns 1 and 4 use a local linear regression, as outlined in McCrary (2008). Columns 2, 3, 5, and 6 fit a 6th-order polynomial in FICO on either side of the cutoff. Heteroskedasticity-robust standard errors in parentheses. (***) significant at 1 percent, $(* *)$ significant at 5 percent, $(*)$ significant at 10 percent. 
TABlE 7. Securitization Rates During the Enforcement of Anti-Predatory Lending Laws in Georgia and New Jersey

\begin{tabular}{r||c|c|c}
\hline \hline Panel A: Georgia & Law Period & Non-Law Period & Difference \\
\hline Georgia & .985 & .963 & $.022^{* * *}$ \\
s.e. & $(.001)$ & $(.001)$ & $(.001)$ \\
$N$ & 21,232 & 52,169 & 73,301 \\
\hline Neighboring states (AL, NC, SC, TN, FL) & .989 & .972 & $.018^{* * *}$ \\
s.e. & $(.000)$ & $(.000)$ & $(.001)$ \\
$N$ & 72,451 & 192,027 & 264,478 \\
\hline Difference & $-.004 * * *$ & $-.008^{* * *}$ & $.005 * * *$ \\
s.e. & $(.001)$ & $(.001)$ & $(.001)$ \\
$N$ & 83,583 & 244,196 & 337,779 \\
\hline \hline Panel B: New Jersey & Law Period & Non-Law Period & Difference \\
\hline New Jersey & .916 & .934 & $-.018^{* * *}$ \\
s.e. & $(.001)$ & $(.001)$ & $(.002)$ \\
$N$ & 36,264 & 104,199 & 140,463 \\
\hline Neighboring states (NY, PA, DE) & .906 & .926 & $-.020^{* * *}$ \\
s.e. & $(.001)$ & $(.001)$ & $(.001)$ \\
$N$ & 76,209 & 223,600 & 299,809 \\
\hline Difference & $.011^{* * *}$ & $.008 * * *$ & .003 \\
s.e. & $(.002)$ & $(.001)$ & $(.002)$ \\
$N$ & 112,473 & 327,799 & 440,272 \\
\hline
\end{tabular}

Notes: For Georgia, Law Period is equal to 1 if the loan was originated between the start of October 2002 and the end of February 2003. The sample period is six months longer than the Law Period on either end: from April 2002 to August 2003. For New Jersey, Law Period is equal to 1 if the loan was originated between the start of December 2003 and the end of May 2004. Similarly, the sample period is six months longer than the Law Period on either end: from June 2003 to November 2004. Heteroskedasticity-robust standard errors in parentheses. (***) significant at 1 percent, $(* *)$ significant at 5 percent, (*) significant at 10 percent. 


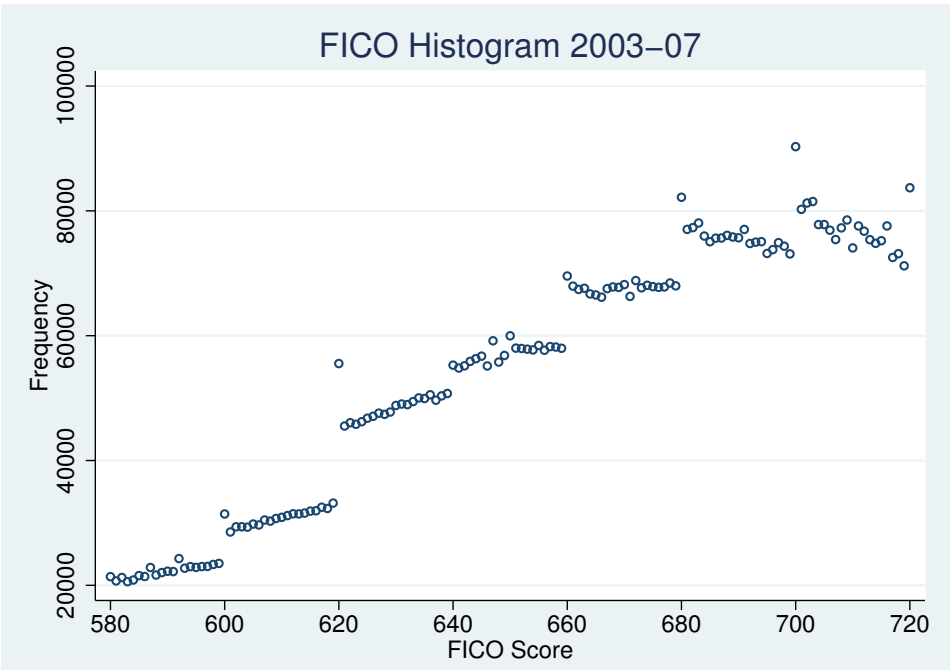

FIGURE 1. Discontinuities in the density of mortgages by credit score. Data source: Lender Processing Services Applied Analytics, Inc. Sample frame of firstlien, non-buydown, owner-occupied, single-family mortgage loans originated between January 2003 and December 2007.

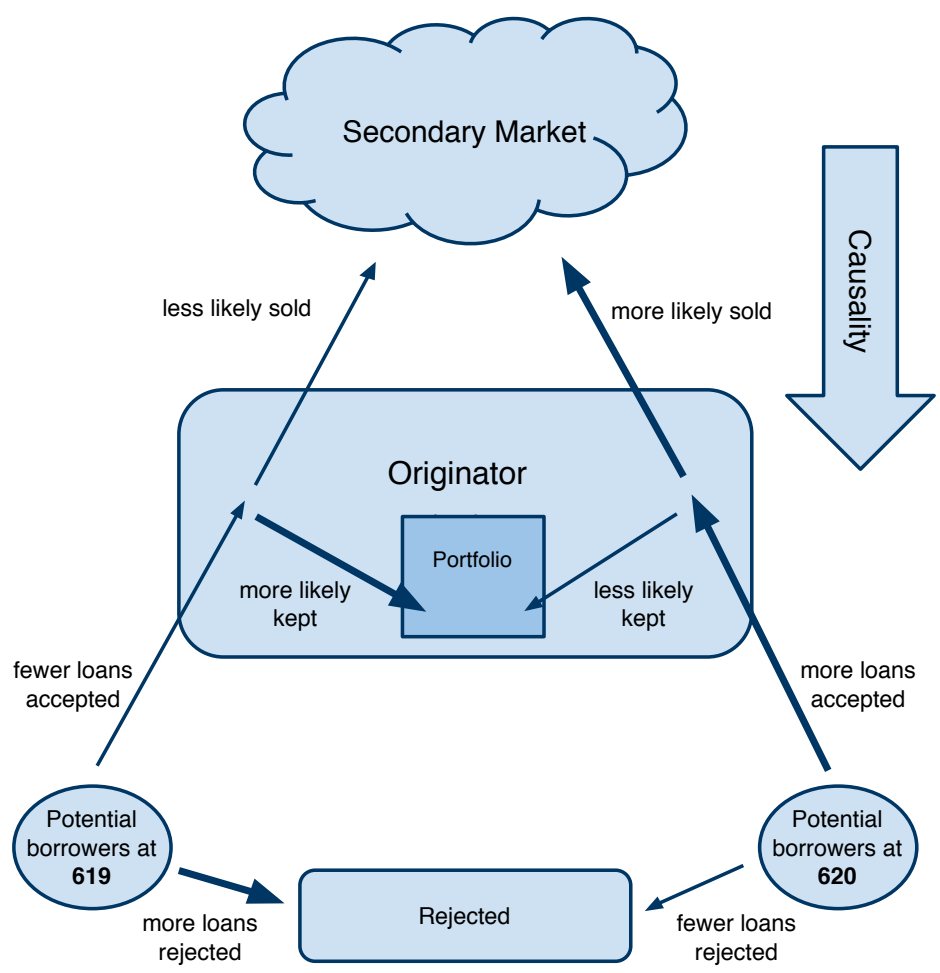

FIGURE 2. Securitization rule-of-thumb theory 


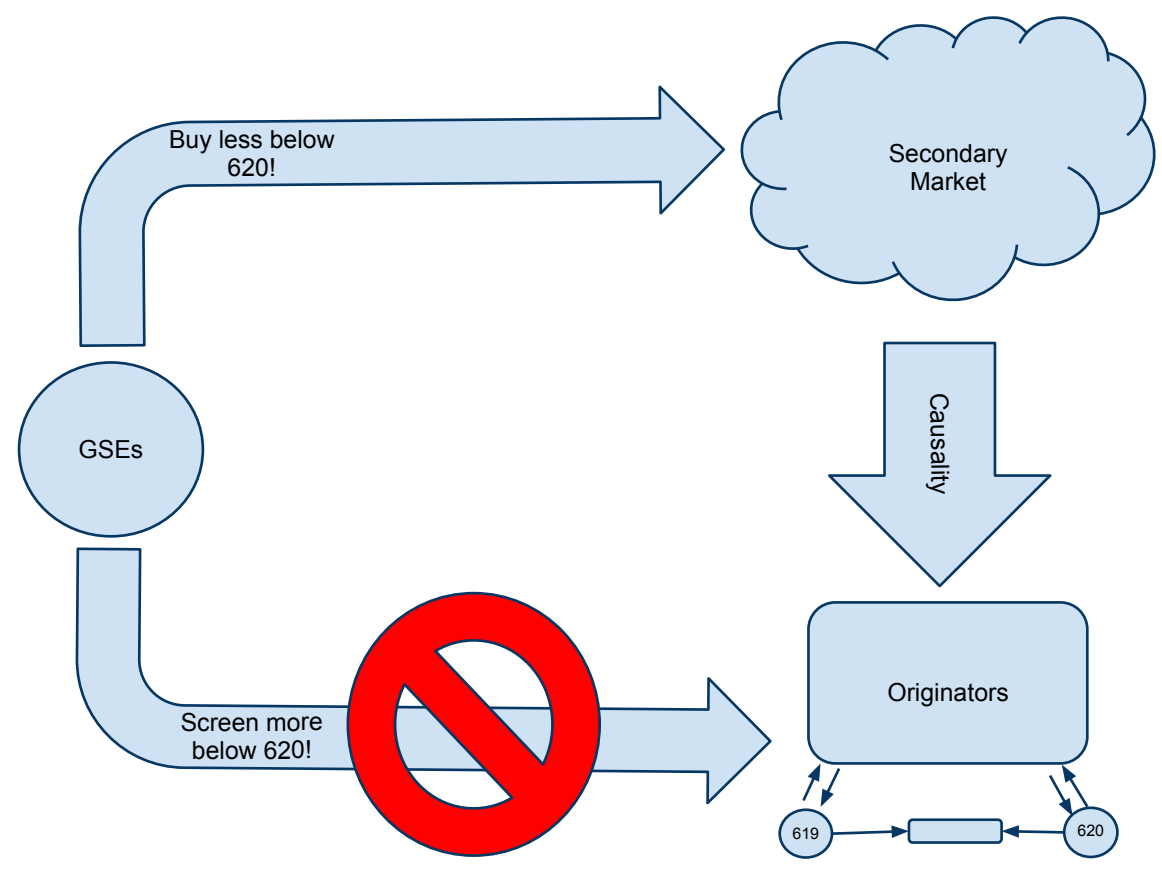

FIGURE 3. Identifying assumptions of RD research design

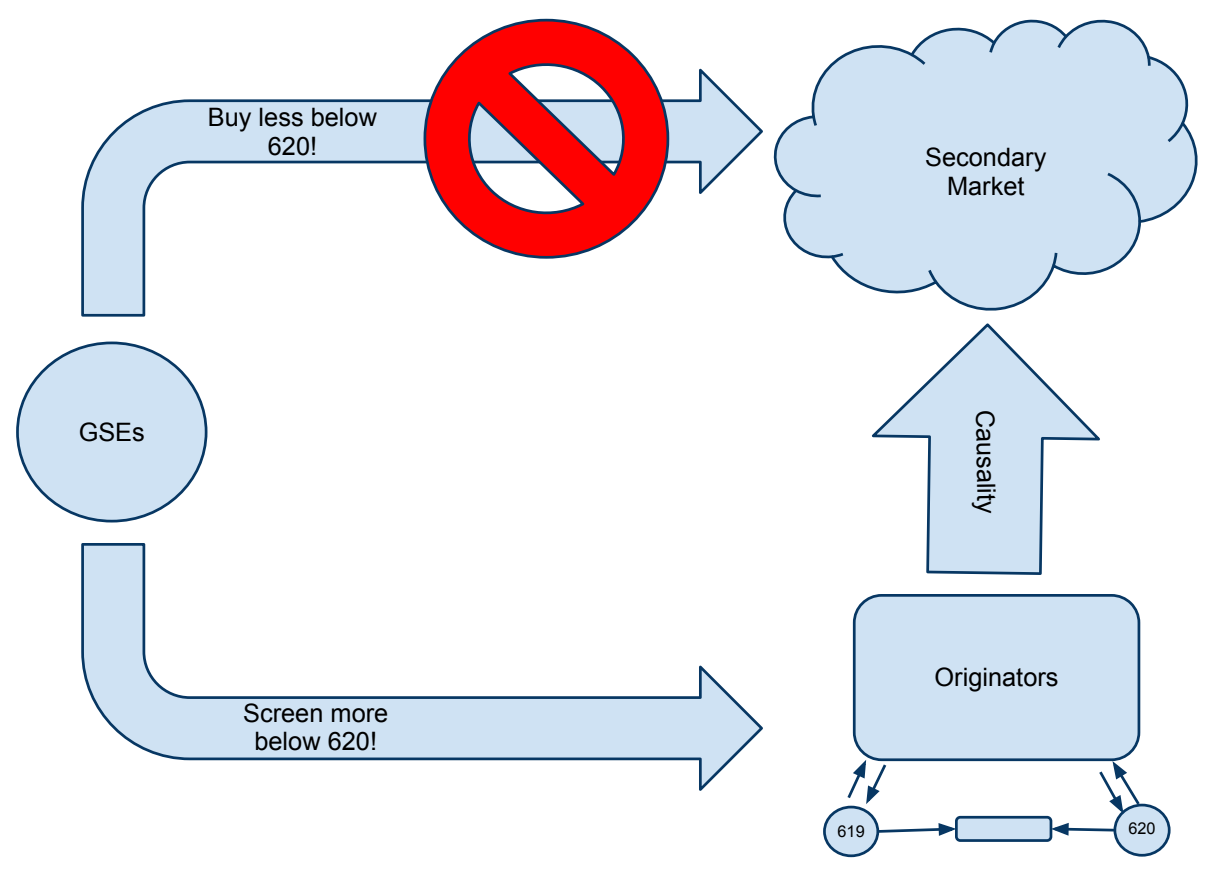

FIGURE 4. Institutional evidence on GSE guidance 


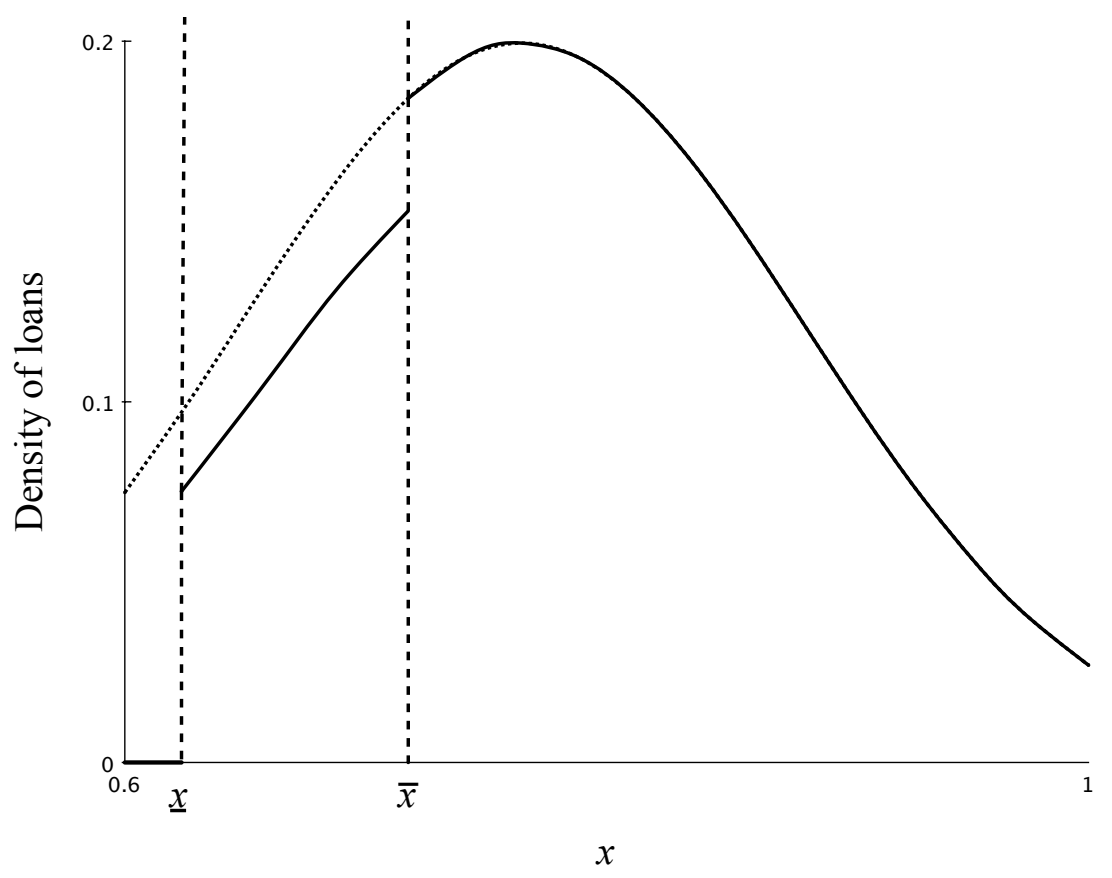

FIGURE 5. Discontinuity in the density of loans

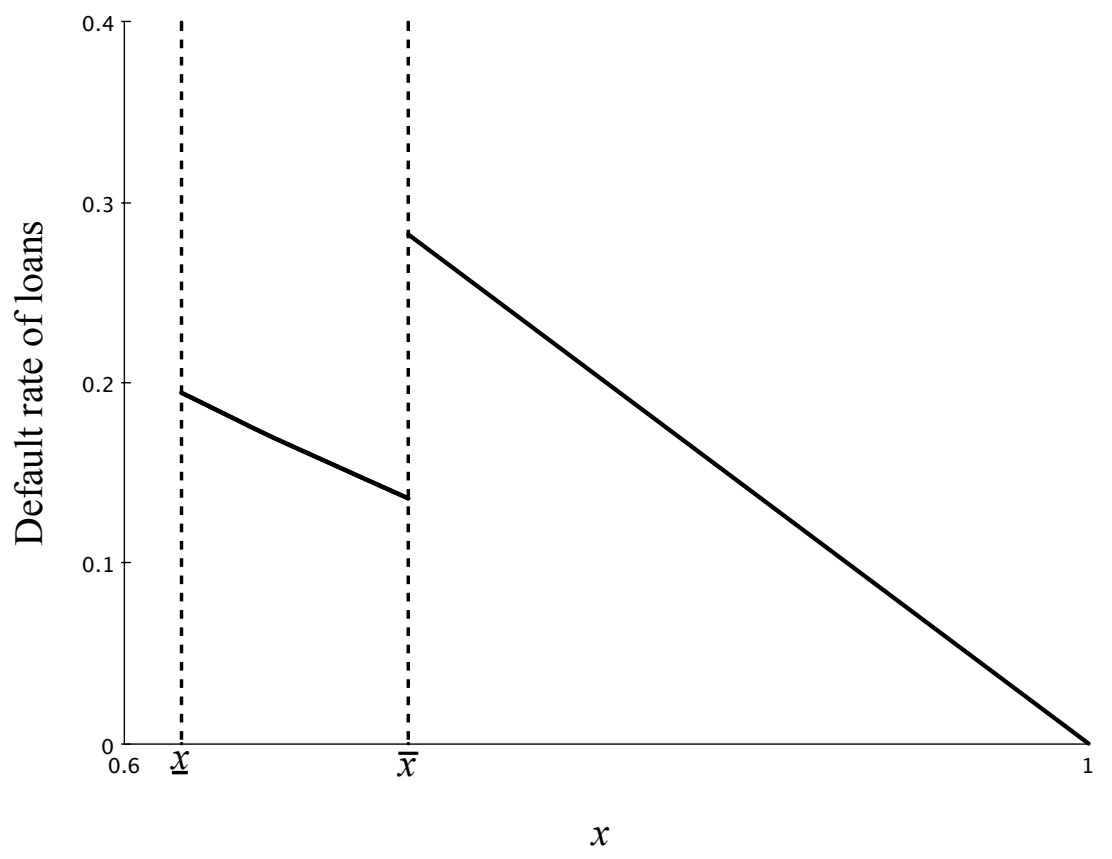

FiguRE 6. Discontinuity in the default rate of loans 


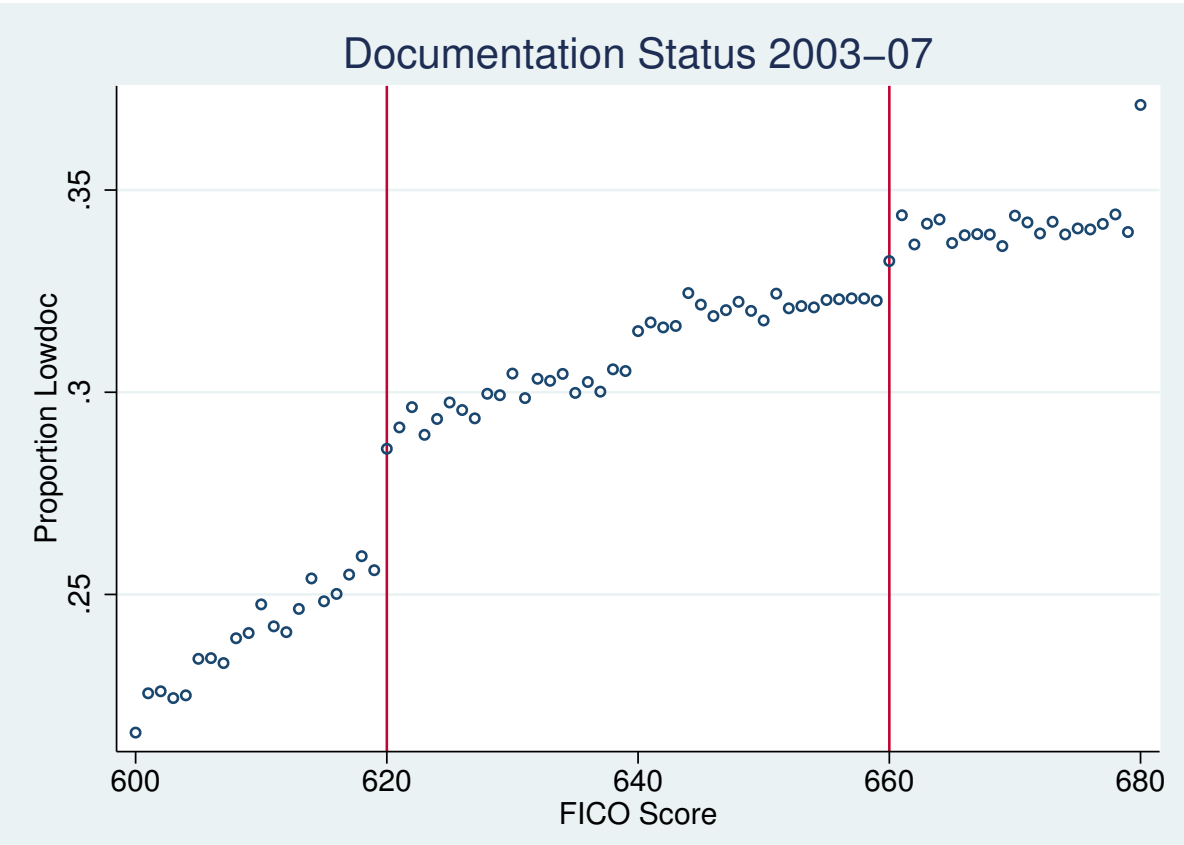

FIGURE 7. Proportion low documentation by FICO. Data source: Lender Processing Services Applied Analytics, Inc. Sample frame of first-lien, non-buydown, owner-occupied, single-family mortgage loans originated between January 2003 and December 2007. 

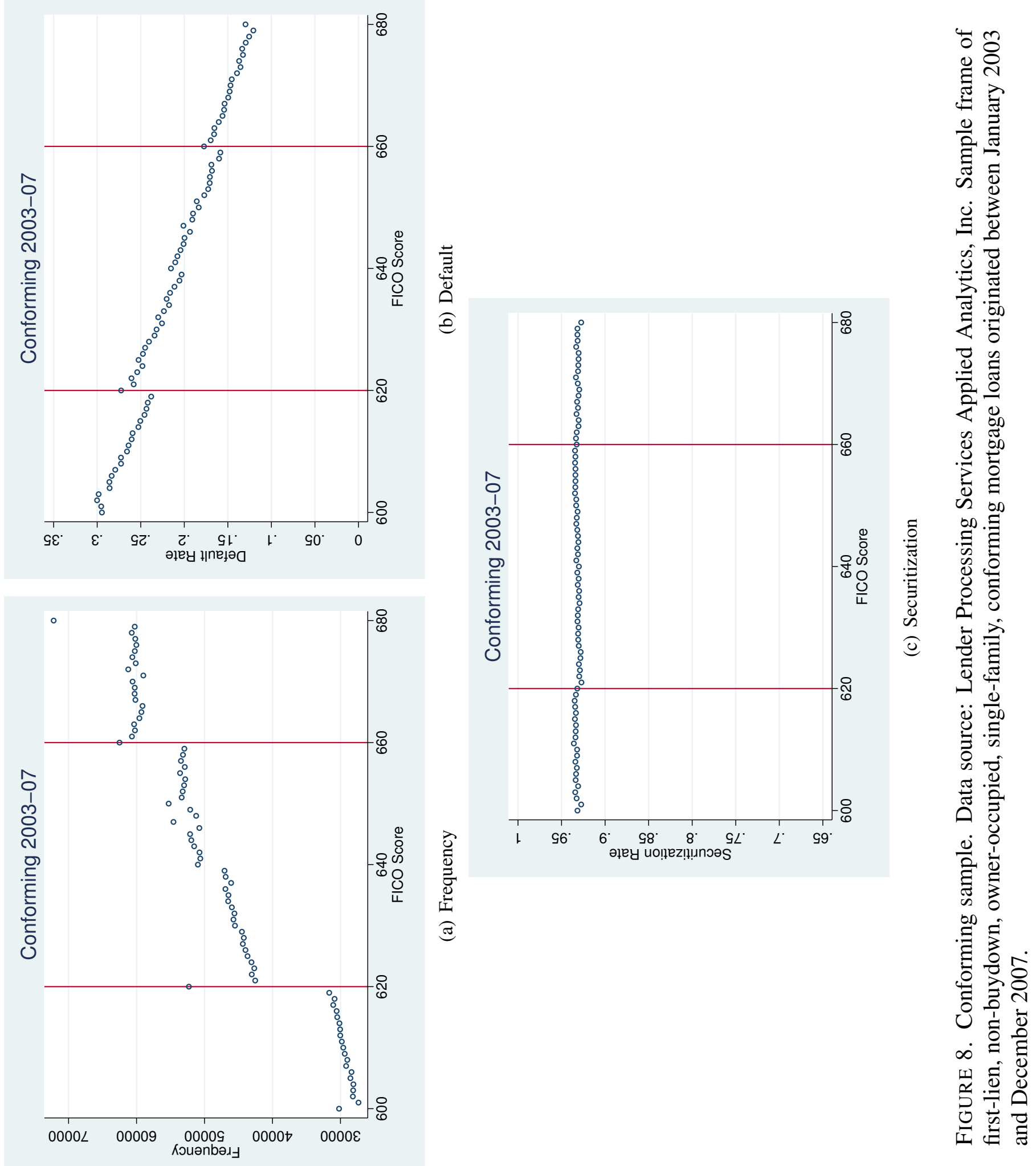

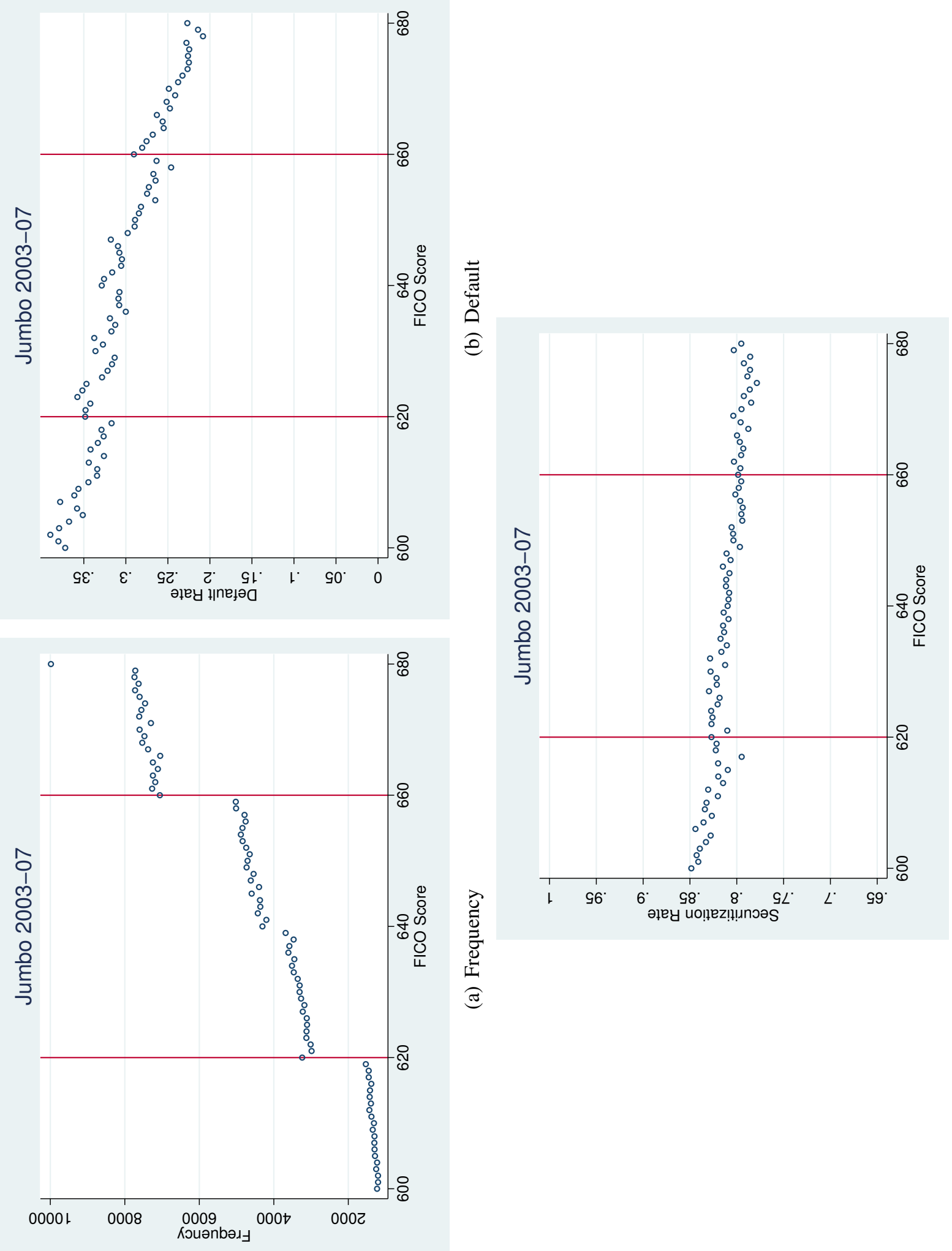

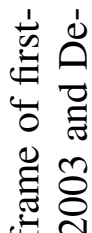

莒言

$\dot{\Xi}$

is

궁

สีํㅗㅀ

D.

宅芯

(0)$$
\text { . }
$$

.

$>\pi$

थे

bo छ

㤩是

D

흘

ए)

$\ddot{0}$

e

రิ ఫ్లే

䒕

ث)

葛

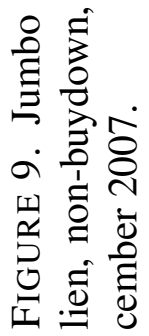



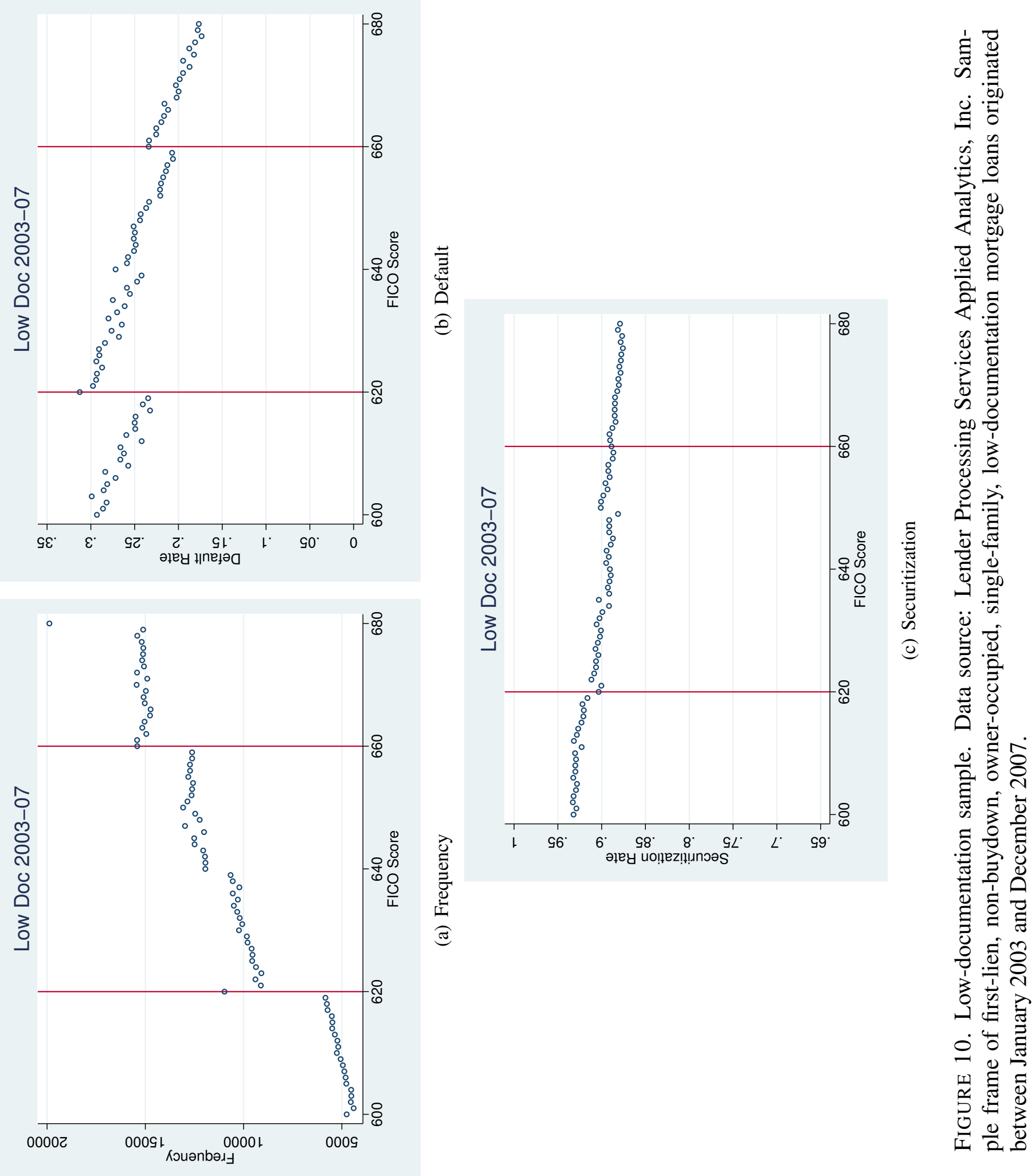

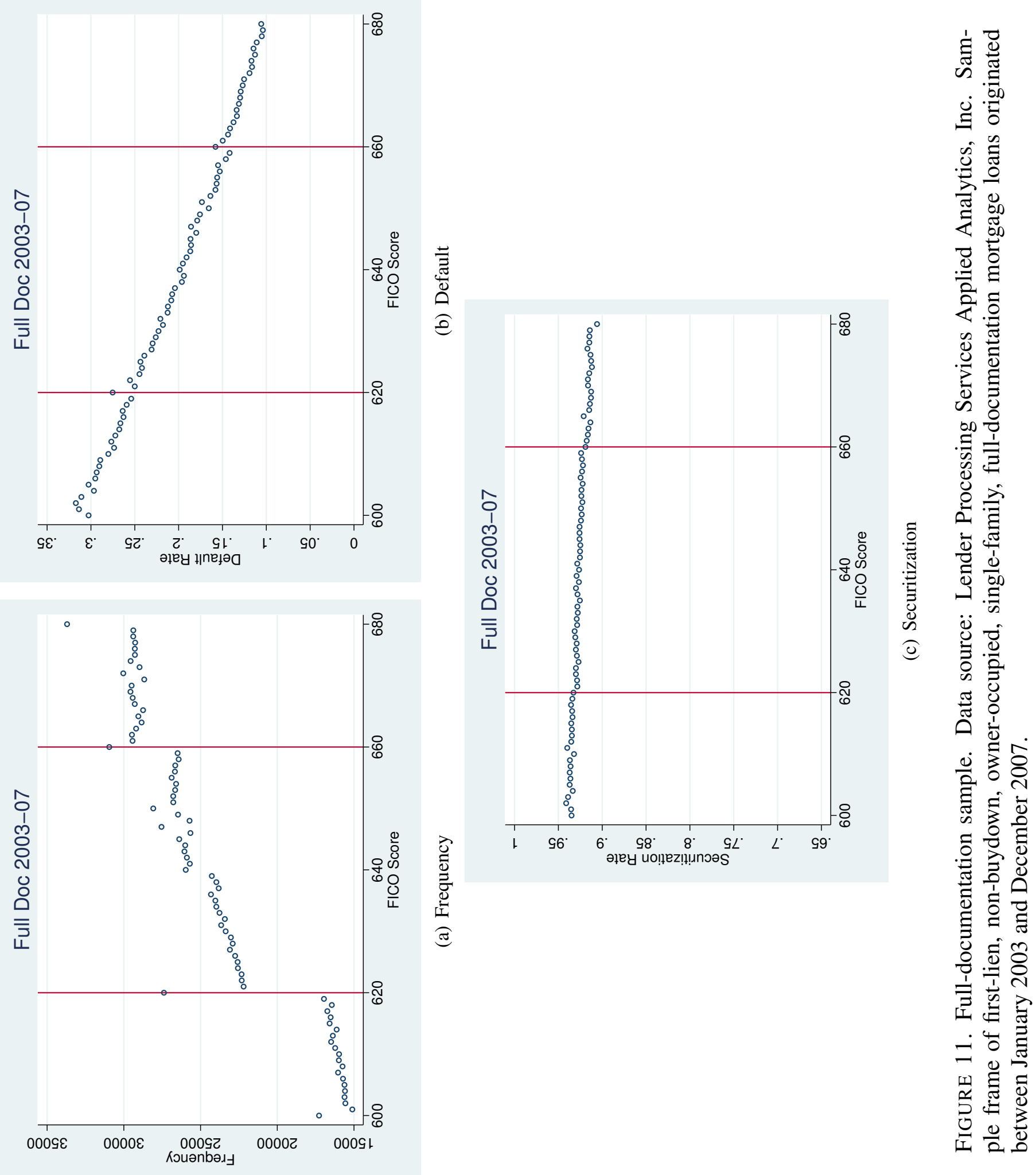

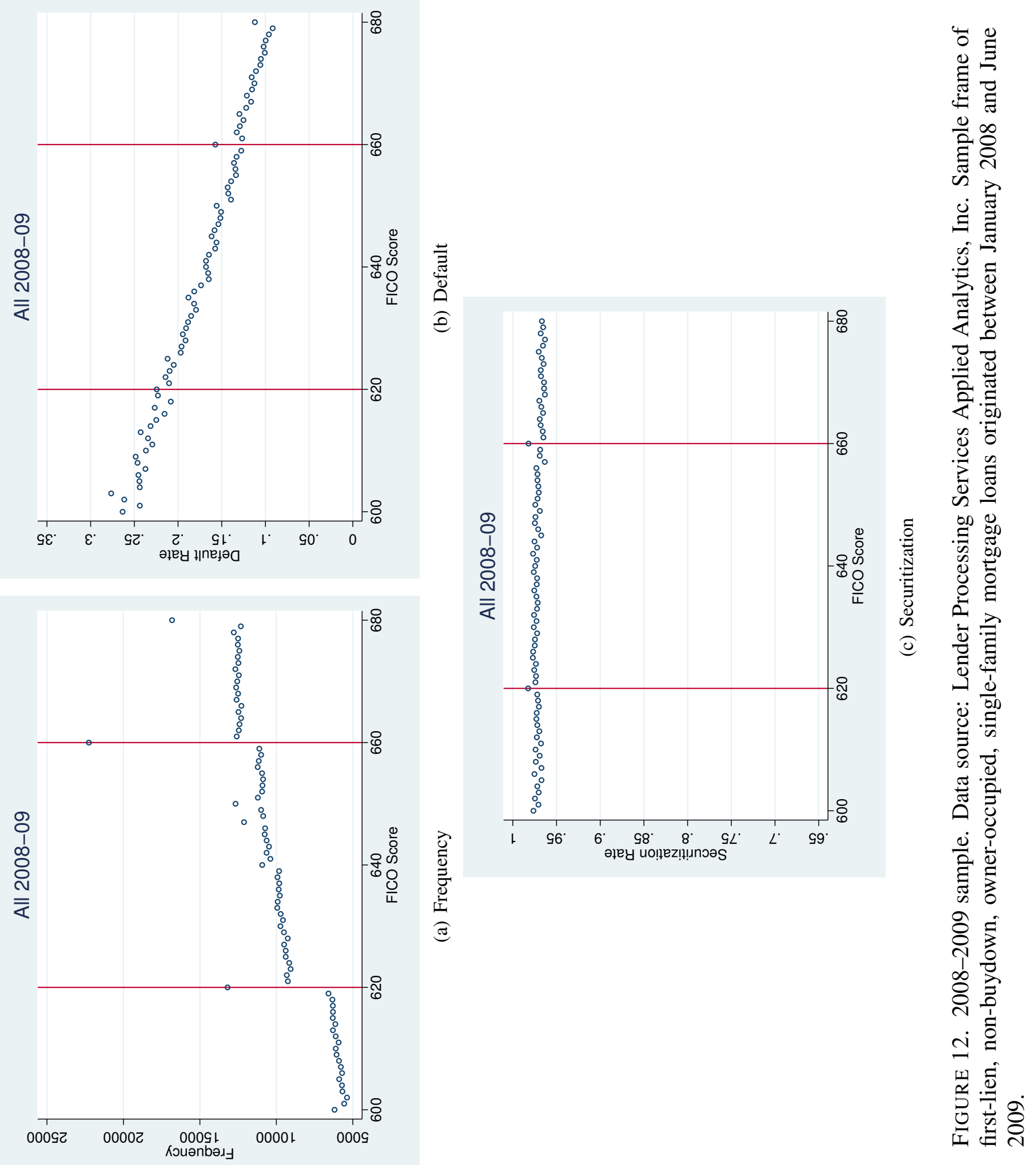

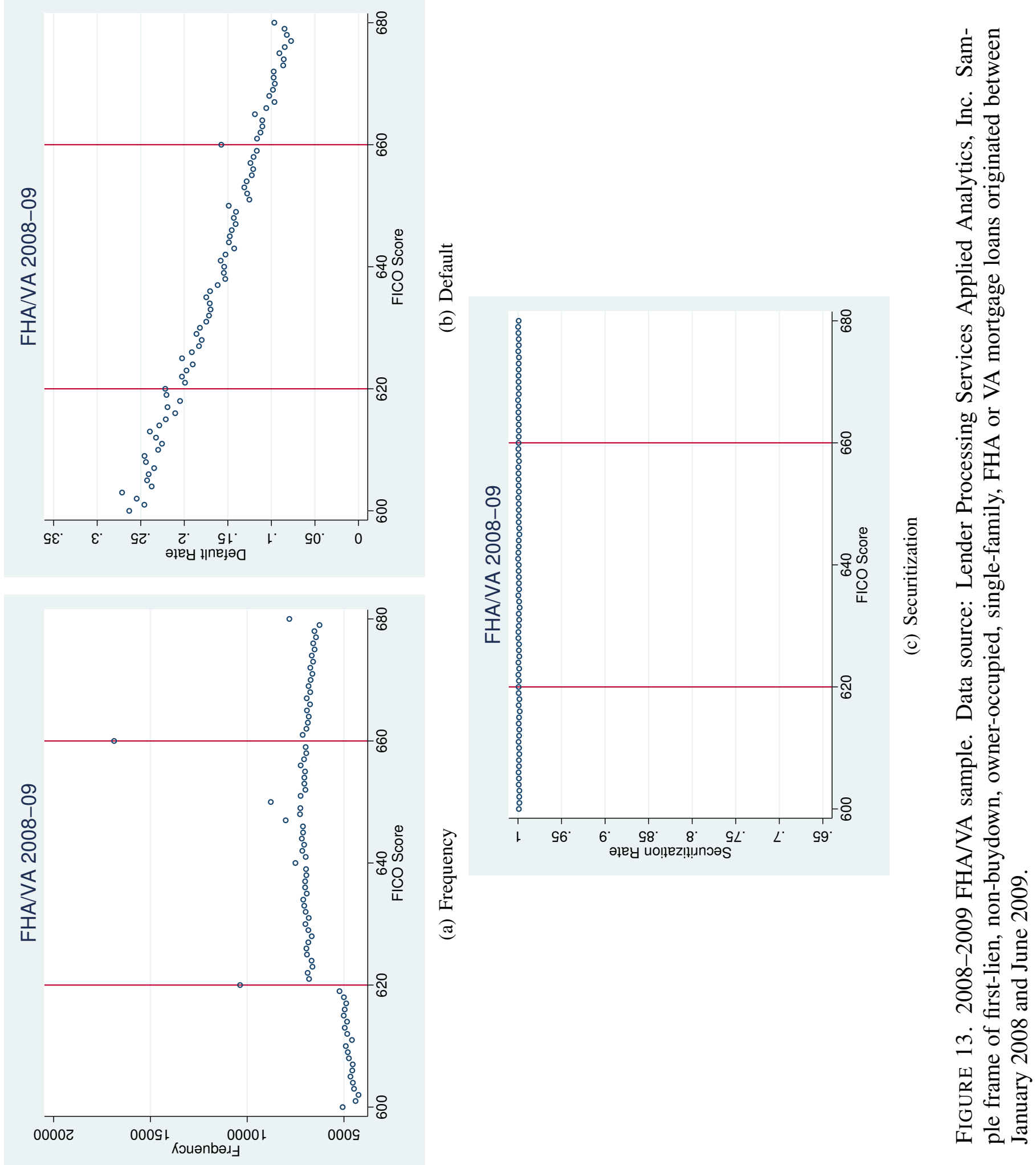

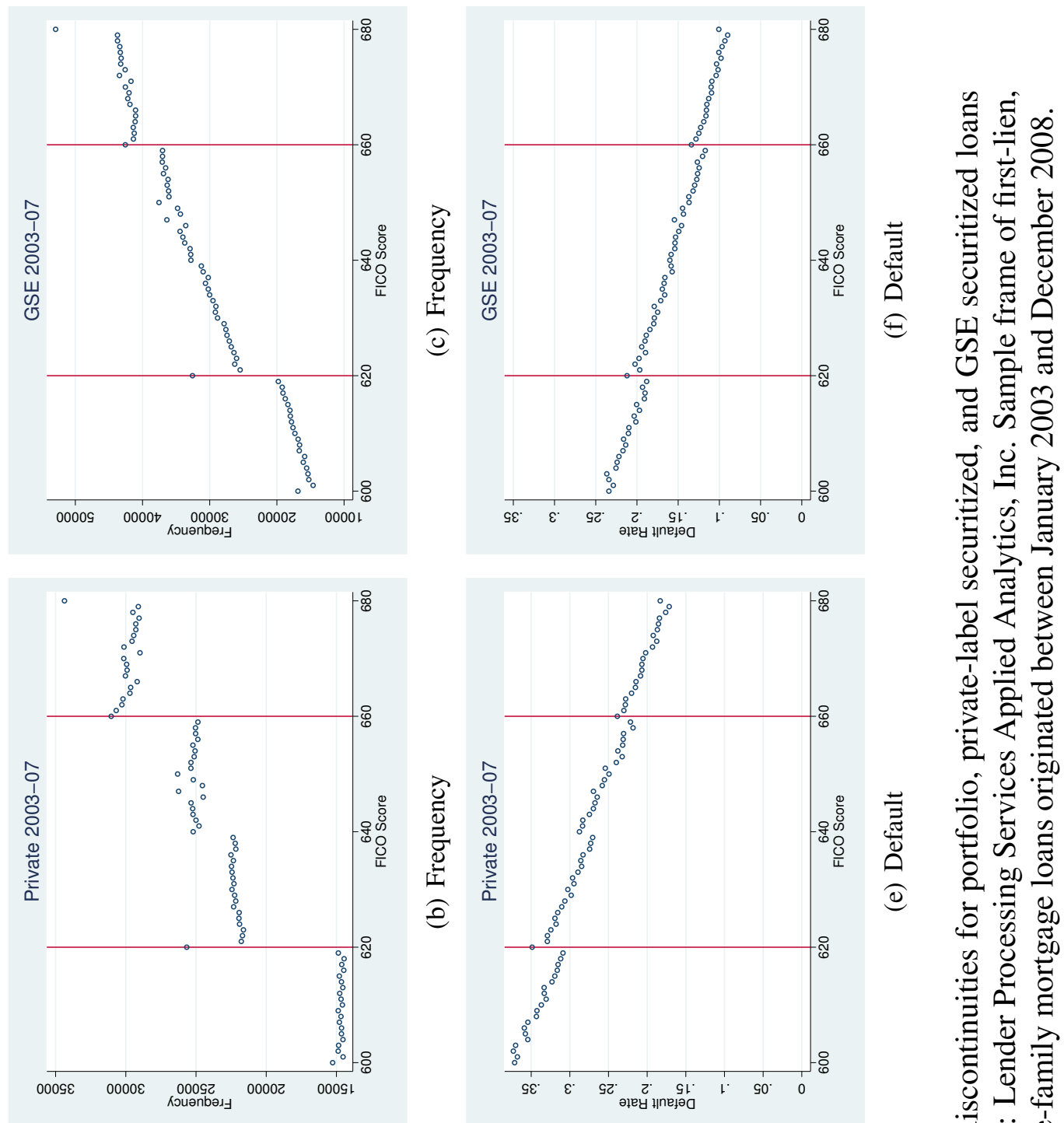

ఫ્ठ :

包焉

ष

정

胥 를

: 己元

능

อ
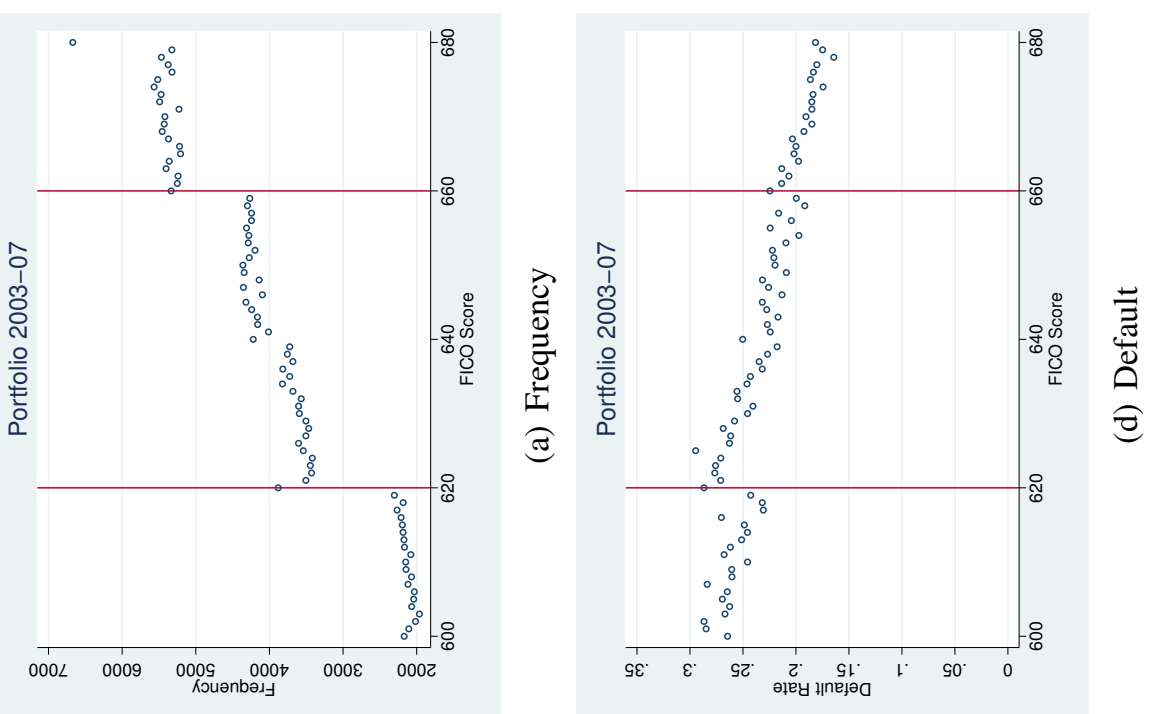

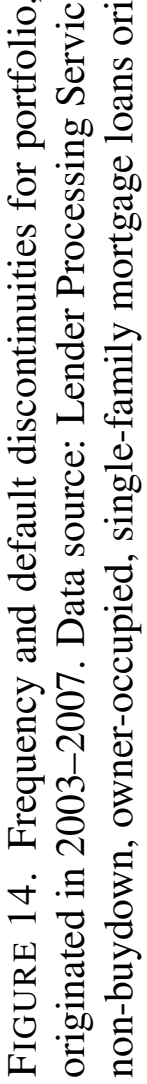




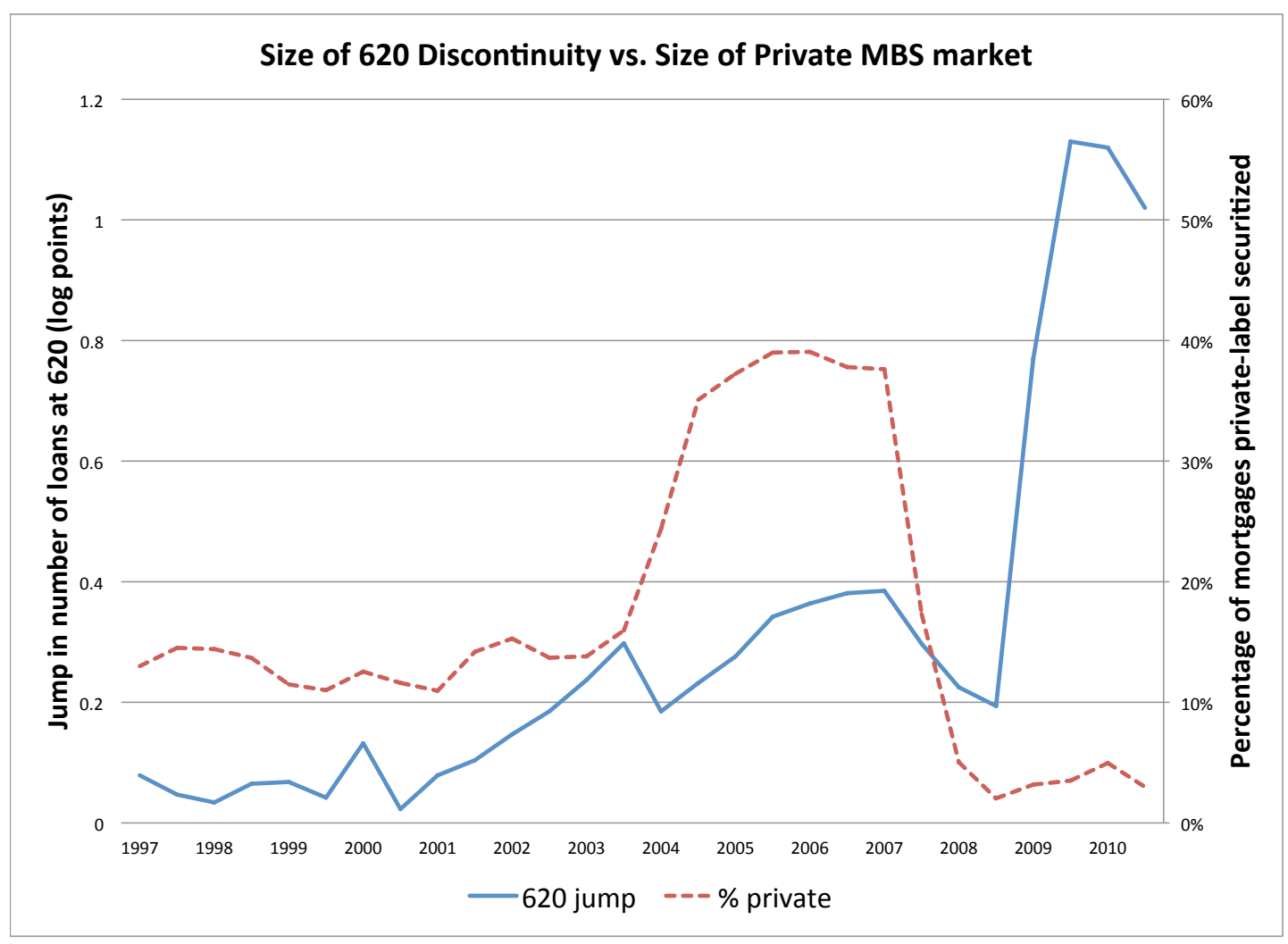

FIGURE 15. Size of 620 discontinuity vs. size of private-label MBS market. Data sources: Lender Processing Services Applied Analytics, Inc. for the 620 discontinuity, Mortgage Market Statistical Annual for the private-label MBS market. 